\title{
1. EINFÜHRUNG
}

Die folgende Arbeit setzt sich mit einer Gruppe von Quellen auseinander, die der Aufmerksamkeit der bisherigen Forschung weitgehend entgangen ist: die Kompendien des französischen und burgundischen Heroldswesens im Spätmittelalter.

$\mathrm{Zu}$ diesem relativ umfangreichen Quellencorpus wurden bisher nur wenige Seiten publiziert. Dies mag verwundern, bilden diese Handschriften doch den wesentlichen Schlüssel zum Verständnis eines Amtes, dessen besondere Bedeutung für die spätmittelalterliche Adelskultur schon seit Jahren bekannt ist ${ }^{1}$. Doch führte dies bisher kaum zu weiterführenden Forschungsvorhaben. Und wenn bereits die Herolde selbst in der Forschung noch immer ein Schattendasein fristen, so erklärt sich auch, warum die Heroldskompendien bisher fast noch gar nicht zur Kenntnis genommen wurden.

Damit wird dieser Quellengruppe jedoch erheblich Unrecht getan. Deren Texte nämlich betreffen nicht nur Amt und Geschichte des Heroldswesens allein. Entsprechend dessen Aufgaben und Interessen werden hier vielmehr in erster Linie verschiedene Bereiche der spätmittelalterlichen Adelskultur und des adeligen Wissens verhandelt. So finden sich neben den obligatorischen Anleitungen zum Wappen- und Turnierwesen auch Texte zur Begründung und Durchführung gerichtlicher Zweikämpfe, zum Ablauf adeliger Obsequien, den Regeln der Kaisererhebung und der Ernennung neuer Könige, Herzöge, Grafen, Barone und Ritter, Übersichten über die französischen Herzöge und Grafen, Genealogien der französischen Könige, Chroniken, Tugendkataloge, kurze Unterweisungen weltlicher wie religiöser Natur sowie, wenn auch nur vereinzelt, auch Ritter- und Adelstraktate. Zum Heroldswesen selbst finden sich darüber hinaus Texte zu dessen (mythischen) Ursprüngen unter Julius Caesar und während der Belagerung von Karthago sowie Darstellungen zur Ernennung neuer Herolde, zu deren Schwur, ihrer Ausbildung wie ihren diversen Aufgaben, Rechten und Privilegien.

Spätestens im 15. Jahrhundert im Zentrum der adeligen Kultur angelangt, besaßen die Herolde nicht nur eine erhebliche öffentliche Präsenz. Sie verfügten auch über einen nicht unbedeutenden Einfluß auf die öffentliche Wahrnehmung der einzelnen Adligen wie auf die allgemeinen Vorstellungen von Ruhm und Ehre. Wenn Gert Melville, der sich bereits in mehreren Arbeiten grundlegend zur sozialen Funktion der Herolde und deren Selbstzeugnissen geäußert hat, schon die Auseinandersetzung mit dem Heroldswesen als solchem als exzellenten Einblick in die Mentalität und das Bewußtsein der aristokratischen Gesellschaft des späten Mittelalters beschreibt ${ }^{2}$, so kann sich dieser Eindruck mit den hier zur Untersuchung stehenden Heroldskompendien nur noch verstärken. Denn diese sind

1 Auf die Notwendigkeit einer näheren Beschäftigung mit dem Heroldswesen und deren besonderen Erkenntniswert verwies bereits PARAVICINI, Ritterlich-höfische Kultur, S. 78, sowie mehrfach vor allem Gert MelviLle, Hérauts et héros, S. 81; DeRS., Brief, S. 69-71.

2 Vgl. Ders., Hérauts et héros, S. 81. 
nichts anderes als der Ausdruck der Auseinandersetzung der Herolde mit der adeligen Kultur (und ihrer Rolle in dieser).

Ihre Kompendien - hier verstanden als kompilatorisch zusammengetragene Sammlungen von Unterweisungen, Lehrtexten und Wissenssammlungen zu einem bestimmten Thema - repräsentieren dabei nicht nur die Interessen und das spezifische Wissen eines besonderen Amtes. Sie sind zugleich Spiegel einer wenn man so will - populären, da alltäglichen Wissenskultur des Adels. Umfangreiche theoretische Abhandlungen über den Stand und den Statuts des Adels sucht man hier vergebens. Derartige Inhalte sind in den entsprechenden Texten nur implizit enthalten. Statt dessen ist hier vor allem das versammelt, was Philippe Contamine einmal etwas verächtlich als »la menue monnaie de la culture nobiliaire « ${ }^{3}$ bezeichnete: der Kleinkram der adeligen Kultur bzw. der adeligen Bildung. Doch gerade damit schienen die Heroldskompendien das zu repräsentieren, was im allgemeinen, landläufigen Interesse der Herolde wie des Adels lag. Die Heroldskompendien trugen dabei nicht nur einige wesentliche Texte der spätmittelalterlichen Adelskultur zusammen. Gerade in ihrer Dichte relevanter Texte und Themen gerieten sie letztlich selbst zu einer Referenz der adeligen Wissenskultur ihrer Zeit ${ }^{4}$.

Dennoch wurden die Herolde und deren Textsammlungen in der bisherigen Forschung weitgehend ignoriert. Einer der Gründe hierfür mag sicher in dem beachtlichen Quellenbestand liegen, der uns aus dem 15. Jahrhundert in den Bibliotheken und Archiven erhalten ist und der in großen Teilen noch immer seiner Erschließung harrt ${ }^{5}$. Zieht man zum anderen - wie Michael Jones - einen Vergleich der französischen Situation zu jener in England, wo Herolde noch immer in Amt und Würden sind, so ist sicherlich auch das Fehlen einer solchen institutionellen Kontinuität bis in die heutigen Tage der Erforschung des französischen Heroldswesens abträglich gewesen ${ }^{6}$. Zumal es in Frankreich nie eine so klar organisierte,

${ }^{3}$ Contamine, Traités de guerre, S. 364.

${ }^{4} \mathrm{Zu}$ den Begriffen »Wissen « und »Wissenskultur « vgl. vor allem die Arbeiten des Frankfurter Sonderforschungsbereiches $435 »$ Wissenskultur und gesellschaftlicher Wandel«, hier programmatisch FRIED, KAILER, Einleitung. Ganz ähnlich wie dort wird auch in der vorliegenden Untersuchung der Wissensbegriff über die methodisch gesicherten Kenntnisse der Philosophie und der Wissenschaft hinaus im Sinne von Alltagswissen gebraucht, »Wissenskultur « ihrerseits als die einer jeweiligen Kultur besondere »Kultur des Wissens « als auch als das spezifische Wissen einer Kultur verstanden, welches die Kultur konstituiert. Das wesentliche Ziel der vorliegenden Arbeit ist es, die Heroldskompendien überhaupt erst als Quellengruppe zu erschließen, sie in ihren zeitgenössischen Kontext einzuordnen und ihr etwaiges Erkenntnispotential herauszuarbeiten. Doch wäre es sicherlich ebenso interessant wie fruchtbar, deren Analyse unter den Fragestellungen und methodischen Leitlinien des Frankfurter Sonderforschungsbereiches weiterzuverfolgen.

5 Vgl. Melville, Hérauts et héros, S. 81.

6 Vgl. Jones, Vers une prosopographie des hérauts, S. 1399f. Zur Kontinuität des Heroldswesens in England, das bereits 1417 die ersten gemeinsamen Privilegien erhielt und seit 1484 bis heute im College of Arms organisiert ist und dem damit erhöhten Forschungsaufwand vgl. u. a. College of Arms (Hg.), Heralds' Commemorative Exhibition, oder auch - mit Biographien aller bisherigen englischen Herolde - GoDFREY, History of the College of 
zentrale Institution gab wie die des englischen College of Arms ${ }^{7}$. Das französische Heroldswesen ging bereits im Verlauf des 16. Jahrhunderts nieder und wurde 1615 in wesentlichen Teilen seiner Aufgaben durch die juges d'armes ersetzt, welche selbst wiederum mit der Monarchie ihr Ende fanden ${ }^{8}$.

Der Hauptgrund jedoch mag wohl in der weitverbreiteten, unmittelbaren Assoziierung des Heroldswesens mit der Heraldik liegen, hier als Wappenkunde verstanden, welche das Bild in einem empfindlichen Maße verengt. Dabei handelt es sich beinahe um einen Teufelskreis, da das Heroldswesen bisher auch fast ausschließlich bei Heraldikern Beachtung fand ${ }^{9}$. Es liegt in der Natur der Sache, daß die Beschreibung des Heroldswesens bei diesen stets eine gewisse Verkürzung erfuhr, die dann auch außerhalb der Wappenkunde bestehen bleibt, wenn sie nicht hinterfragt wird. Und so geschieht es häufiger, daß die Grundzüge des Heroldswesens in der französischsprachigen Forschung immer wieder mit der Hilfe des »Traité d'héraldique« von Michel Pastoureau erläutert werden, selbst wenn das entsprechende Kapitel deutlich einschränkend mit »Les hérauts d'armes et le système armorial des XIVe et XVe siècles « überschrieben ist ${ }^{10}$. Dies hinterläßt Spuren ${ }^{11}$. Und so partizipieren die auf diese Weise meist nur als Kenner der Wappen

Arms. Sir Anthony Richard Wagner, der für die bisher einzigen umfassenderen Monographien zum Heroldswesen verantwortlich ist, war selbst königlicher Herold Richmond und wurde später zum obersten englischen Wappenkönig Garter ernannt. Für die anhaltende Präsenz des College of Arms in der Öffentlichkeit sei hier nur auf deren Internetauftritt (www.college-of-arms.gov.uk) verwiesen.

7 Zum College der französischen Herolde siehe unten, S. $227 \mathrm{f}$. und $410 \mathrm{f}$.

8 Grolée-VIRville, Les d'Hozier, S. 16f. Dennoch ging das Amt der Herolde nicht verloren, nur ist die Forschungssituation in der Neuzeit noch trostloser. Für einen kurzen Überblick siehe PARRY, Les hérauts d'armes. Weitere Belege für die späteren Tätigkeiten der Herolde finden sich bei KLESMANN, »Bellum solemne«, S. 40-43, 58-73. Ein beredtes Zeugnis der Tätigkeiten eines französischen Herolds aus der Mitte des 17. Jahrhunderts bietet die meines Wissens bisher unbeachtet gebliebene Handschrift Paris, BnF, n.a. fr. 10263 (»Second livre des coppies des commissions, missives et notte de voiages que j'ay faictz comme herault d'armes de France au tiltre des Valois«, 1643-47), eine Sammlung von Briefen und anderen Materialien der beruflichen Aktivitäten von Fabien Gardé, Herold Valois, die er als zweiten Band seiner Memoiren plante.

9 Vgl. für die ältere deutsche Literatur u. a. BERCHEM, Herolde. In der englischsprachigen Forschung ist v. a. auf das immer wieder zitierte Werk von Anthony Richard Wagner, Heralds and Heraldry, aber auch auf Rodney DENNYs, Heraldry and the Heralds, zu verweisen. Und auch der den militärischen Funktionen der Herolde gewidmete Beitrag von Paul ADAMEVEN ist überschrieben mit »Les fonctions militaires des hérauts d'armes. Leur influence sur le développement de l'héraldique«.

10 Vgl. Pastoureau, Traité d'héraldique, S. 61-63. Dies ist nicht anders bei dem eben genannten Standardwerk von Anthony WAGNER, Heralds and Heraldry. Auch wenn dieses umfangreicher und damit inhaltlich breiter gefaßt ist, deutet auch hier der Untertitel bereits auf eine thematische Einschränkung in der Auseinandersetzung mit dem Heroldswesen hin: »An Inquiry into the Growth of the Armorial Function of Heralds «.

11 So erwähnt z. B. Françoise DE Gruben in ihrer Abhandlung zu den Ordensfesten des Ordens vom goldenen Vlies zwar die Bedeutung des Wappenkönigs Toison d'or bei besonderen Botendiensten und der Information der neugewählten Ordensmitglieder über ihre Wahl, doch kommt sie erst dann - so scheint es - auf dessen eigentliche Aufgaben zu sprechen: »Il assurait, bien sûr, la fonction de roi d'armes, c'est-à-dire qu'il était chargé de toutes les ques- 
bekannten Herolde noch immer an dem recht faden Image, welches die Heraldik trotz so innovativer wie aufschlußreicher Arbeiten wie denen von Michel Pastoureau zur »héraldique imaginaire «12, zur sozialen Bedeutung der Wappen von Werner Paravicini ${ }^{13}$ oder zur Rolle der Wappen als Zeichen und Symbol in dem von Wolfgang Achnitz herausgegebenen Sammelband ${ }^{14}$ bis heute genießt.

Die Tätigkeit der Herolde einzig auf die Heraldik zu beschränken, wäre aber schlichtweg falsch. Sicher, die Herolde haben der Heraldik ihren Namen gegeben. Doch wurde auch unter diesem Begriff einst mehr verstanden als allein die Wissenschaft der Wappen: nämlich die Wissenschaft der Herolde ${ }^{15}$. Die Auseinandersetzung mit den Wappen umfaßte dabei nur einen, wenn auch einen wesentlichen Teil der Beschäftigung der Herolde. Das Heroldswesen selbst jedoch, zumal am Ende des Mittelalters, war bedeutend mehr!

\subsection{Das spätmittelalterliche Heroldswesen (Frankreich und Burgund) ${ }^{16}$}

\subsubsection{Geschichte und Aufgaben des Heroldswesens}

Die Ursprünge des Heroldswesens liegen in der sich herausbildenden ritterlichen Turnierkultur des hohen Mittelalters und den aufkommenden heraldischen Gewohnheiten ihrer Teilnehmer in der zweiten Hälfte des 12. Jahrhunderts ${ }^{17}$. Aus

tions relatives aux armoiries « (DE GRUBEN, Chapitres de la Toison, S. 35). Ein ähnliches Beispiel findet sich im Beitrag von Jean-Luc RouILLER zum Testament des Jean Piat, Herold Genève, wo es am Ende heißt: »Mais, paradoxalement, notre héraut ne parle jamais de ses armoiries, lui qui avait été le spécialiste de celles des autres « (RouILLER, Les habits du héraut, S. 131). Beide verweisen in ihrer Auseinandersetzung mit den Herolden auf Pastoureau, Traité d'héraldique.

12 Vgl. zum Überblick Pastoureau, Introduction.

13 Vgl. Paravicini, Gruppe und Person.

14 Vgl. neuerdings den anspruchsvollen Sammelband AchnitZ (Hg.), Wappen als Zeichen; sowie insbesondere die Arbeiten von Christoph Weber (Braunschweig) zu den Wappen in den italienischen Kommunen, vgl. Weber, Exempla; Ders., Eine eigene Sprache; sowie dessen Dissertation DeRs., Zeichen der Ordnung. Für ein anderes Verständnis der Wappen in der vorrangig auf das Visuelle ausgerichteten Welt des späten Mittelalters vgl. auch KEEN, Chivalry, S. 128-134.

15 Das französische Adjektiv »héraldique« ist erstmals 1680 im Wörterbuch des Pierre RICHELET (Dictionnaire, Bd. I, S. 399) belegt, hier die Wappen betreffend. Die substantivierte Form erscheint im Französischen erst im 19. Jahrhundert. Ihr deutsches Pendant »Heraldik « wurde um 1700 entweder aus dem Französischen oder auch aus dem Neulateinischen entlehnt. Vgl. Heraldik, in: PFEIFER, Etymologisches Wörterbuch, Bd. I, S. 532.

16 In der nachfolgenden Darstellung soll versucht werden, soweit wie möglich auf die Texte aus den Heroldskompendien und auf Selbstäußerungen der Herolde allgemein zu verzichten, um möglichen Zirkelschlüssen vorzubeugen.

$17 \mathrm{Zu}$ den Ursprüngen des Heroldswesens vgl. vor allem WAGNER, Heralds of England, S. 1-40; Ders., Heralds and Heraldry, S. 25-40; van ANROOIJ, Spiegel van ridderschap, S. 16-28; PARISSE, Le tournoi en France, sowie mit einer umfangreichen Materialsammlung 
der Menge der zu den verschiedenen Turnieren anwesenden fahrenden Spielleute und Unterhalter bildete sich bald eine Gruppe heraus, die sich ganz besonders auf das Erkennen der einzelnen Kämpfer anhand ihrer Wappen und Zeichen verstand - ein Spezialwissen, das sie sich auf den zahlreichen Turnieren in ganz Europa aneigneten, welche sie zur Bestreitung ihres Unterhaltes besuchten. Doch waren sie nicht nur in der Lage, die einzelnen Turnierkämpfer anhand ihrer Wappen zu identifizieren. Auch von deren Taten und bisherigen Erfolgen wußten sie zu erzählen und die einzelnen Ritter angemessen zu präsentieren. Auf die Sieger der Turniere dichteten sie Lobeshymnen und baten gemeinsam mit den anderen Spielleuten auf diese Weise um Geschenke, welche die Turniersieger zum Zeichen ihrer Freigebigkeit gern gaben. Zu dieser Zeit führten die Herolde kein anderes Leben als andere Fahrende. In ihrem Auskommen waren auch sie von der gelegentlichen, willkürlichen Großzügigkeit abhängig, die man ihnen gegenüber walten ließ.

Die Situation änderte sich jedoch mit dem zweiten Drittel des 14. Jahrhunderts, als einige der Herolde ein festes Dienstverhältnis an fürstlichen Höfen erlangten $^{18}$. Von nun an integrierten sie sich mehr und mehr in das höfische Leben. Die veränderte Position der Herolde manifestierte sich in einer eigenen Amtskleidung und ihren besonderen Dienstnamen. Sie begannen, die Wappenröcke ihrer Herren zu tragen und wurden für ihr Amt mit einem speziellen Namen versehen, welcher sich zumeist an einer der Herrschaften ihres Herrn (z.B. Calabre, Gelre, Charolais) orientierte, später aber auch die Devise ihres Herrn (Fusil, Ermine, Noir Lyon) oder die Bezeichnung des Ritterordens (Garter, Toison d'or) aufnehmen konnte, dem sie dienten. Damit gerieten die Herolde alsbald zu wahrhaftigen Repräsentanten ihrer Herren.

Gleichzeitig erweiterte sich der Umfang ihrer Aufgaben in erheblichem Maße. Während sich ihre Funktionen auf den Turnieren bald auch auf deren Ankündigung, verschiedene Ausrufungen im Verlaufe der Veranstaltung sowie das Tragen der Banner der einzelnen Mannschaften und die Assistenz bei der Vergabe der Turnierpreise ausdehnte, nahmen die Herolde bereits seit Anfang des 14. Jahrhunderts auch verstärkt Aufgaben im Kriegswesen wahr ${ }^{19}$. Hier dienten sie bei der Erkennung feindlicher wie der Organisation eigener Truppenteile, bei der Identifizierung der Gefangenen und Gefallenen, oder wurden nach der Schlacht selbst mit der Organisation der Bestattung der Toten betraut ${ }^{20}$. Sie

SEYLER, Geschichte der Heraldik, S. 19-45. Zur frühen Geschichte der Herolde vgl. zudem FoEHR-JANSSENS, La voix et le vêtement, und LÅNGFORS, Le Dit des hérauts.

18 Zur zunehmenden Institutionalisierung und den gesellschaftlichen Hintergründen des Aufstieges der Herolde, sowie zur Interpretation dieser Entwicklung allgemein vgl. vor allem MELVILLE, Hérauts et héros, und DERS., »Un bel office«.

$19 \mathrm{Zu}$ den militärischen Funktionen der Herolde vgl. ADAM-Even, Les fonctions militaires, sowie - wenn auch mit gelegentlichen Ausflügen zu den Sitten der britischen Luftwaffe während des zweiten Weltkrieges - DAVIES, Heralds in Medieval Warfare.

20 Vgl. hierzu die Chronik von Mathieu d'Escouchy, Chronique, Bd. I, S. 285, demzufolge am Abend der Schlacht von Formigny Herolde, Persevanten und Priester bestimmt wurden, um am nächsten Tag die Bestattung der Gefallenen zu organisieren. 
überbrachten oder verkündeten Befehle und wurden zu Botendiensten zwischen den Fronten eingesetzt, um Waffenstillstandsangebote zu übermitteln oder Zweikämpfe zwischen Rittern der gegnerischen Heere zu verabreden. Ihre Kleidung, der Wappenrock ihrer Herren, verlieh den Herolden hierbei die notwendige Immunität ${ }^{21}$.

Ihre Botendienste dehnten sich bald auch auf Friedenszeiten aus, wo sie mit der Überbringung von Briefen und Nachrichten, später vor allem von Bündnisvorschlägen und Kriegserklärungen beauftragt wurden und man ihnen selbst eigenständige Gesandtschaften anvertraute. Ihre von Anfang an intensive Reisetätigkeit, ihre Botendienste und ihre Kenntnis der Höfe wie des Adels fremder Länder gingen dabei Hand in Hand. Sie erhielten freies Geleit und waren von jeder Art Wegegeld befreit ${ }^{22}$. Durch ihre Weltgewandtheit und ihre Erfahrung konnten sie ebenso als Wegbegleiter und Dolmetscher adeliger Herren, von Gästen und Gesandtschaften dienen, wie als Begleiter militärischer Verbände ${ }^{23}$.

Letztlich nahmen sie auch repräsentative Aufgaben während der verschiedensten Zeremonien innerhalb der adeligen Kultur wahr ${ }^{24}$. So sind die Herolde im Verlaufe des 15. Jahrhunderts bei so bedeutenden Feierlichkeiten wie Königskrönungen $^{25}$ und -obsequien ${ }^{26}$, bei zeremoniellen Einritten ${ }^{27}$ oder den Ordensfe-

${ }^{21} \mathrm{Zu}$ den diplomatischen Funktionen der Herolde vgl. RöMHELD, Die diplomatischen Funktionen. $\mathrm{Zu}$ den möglichen Hintergründen der Immunität der Herolde siehe zudem: HiLTMANN, Vieux chevaliers.

22 Vgl. z. B. den Geleitbrief des französischen Königs für den Persevanten Jamais (1415), Viellard, Avezou, Lettres originales, S. 359 oder jenen des Markgrafen von Meißen für seinen Herold Missenland (1421), Codex diplomaticus Saxoniae regiae, Reihe B, Bd. I, IV, S. 95. Zur hohen Mobilität der Herolde vgl. u. a. van AnROoIJ, Heralds, Knights and Travelling, S. 51 f., mit einer beeindruckenden Aufzählung von Beispielen.

23 So geleitete 1463 der Herold Bourgogne Truppen nach Deutschland, die der burgundische Herzog dem Mainzer Erzbischof Adolf von Nassau zur Unterstützung sandte, vgl. Heraudica, sources, $n^{\circ}$ 13986. Für Herolde und Persevanten als Führer und Begleiter burgundischer Gesandtschaft z. B. nach Savoyen, vgl. ibid. no 11772 und 13651, mit zahlreichen weiteren Belegen. Oft wurden Herolde und Persevanten auch adeligen Reisenden zur Begleitung beigegeben. Vgl. hierzu z.B. einen Brief Ottos von Dolen an den Hochmeister des Deutschen Ordens vom 7. März 1451, in welchem er diesem einen Nikolaus, Herold Pfalz, anempfiehlt, der ihn vom Hof des Herzogs von Burgund bis nach Livland begleitet habe, ediert in PARAVICINI, Zeitenwende, hier Nr. 7, S. $435 \mathrm{f}$.

24 Zur Interpretation dieser Aufgabe der Herolde vgl. Melville, »Un bel office«, S. 300304 sowie Ders., Hérauts et héros, S. 89f. Weiteren Aufschluß verspricht die Dissertation, die Nils Bock gerade unter der Betreuung von Martin Kintzinger (Münster) über »Die Funktionen der Herolde. Studie zur höfischen Kommunikation im römisch-deutschen Reich des späten Mittelalters« vorbereitet.

25 So war es z. B. bei der Krönung Karls VII. 1429 in Reims die Aufgabe des obersten französischen Wappenkönigs Montjoye, während der Zeremonie die einzelnen Pairs vor den großen Altar zu rufen ainsi et par la manière qu'il est acoustumé (Enguerran de Monstrelet, La Chronique, Bd. IV, S. 339).

26 Vgl. v. a. GIESEY, »Le roi ne meurt jamais«, S. 121, 197-211, 214-217 und passim. So hielten die Herolde am Sarg des toten Königs Ehrenwache und liefen im Leichenzug meist unmittelbar vor dem Sarg des Toten. Und es war auch der Herold, welcher den Herrscherwechsel während der Zeremonie durch seine Ausrufungen manifest machte, wie z. B. bei den 
sten $^{28}$ der weltlichen Ritterorden stets an zentraler Stelle vertreten. So sei nur an den Fasanenschwur Philipps des Guten erinnert, wo der Wappenkönig Toison d'or, begleitet von einer größeren Zahl weiterer Herolde, den Herzog zum Schwur auffordert und dessen Gelöbnis wie das seiner Begleiter entgegennimmt ${ }^{29}$. Auch wenn die Herolde hierbei nur selten tatsächlich auch als Organisatoren oder Zeremonienmeister fungierten ${ }^{30}$, so zeigt ihre auffallende Präsenz dennoch, über welch symbolisch bedeutende Rolle sie mittlerweile verfügten. Sie waren im Zentrum der adeligen Kultur angelangt.

All diese Veränderungen hatten natürlich Einfluß auf die zunehmende Organisation des Heroldswesens. Hier bildete sich eine klare, dreistufige Ämterhierarchie heraus, an deren Spitze die sogenannten Wappenkönige (roys d'armes) standen, welche jeweils die Verantwortung für die Herolde innerhalb einer Wappenbzw. Turniermark (marche d'armes) wie z. B. der Champagne, Anjou oder Artois innehatten ${ }^{31}$. Ihnen stand zumeist ein Wappenmarschall (maréchal d'armes) als Stellvertreter zur Seite. Die Herolde selbst bildeten die eigentliche Masse des Amtes, zu denen als unterste Stufe dann noch die Persevanten (poursuivants) hinzutraten, die jedoch kaum mehr als Vollmitglieder des office d'armes verstanden

Obsequien Karls VII.: Et lors le herault dit ce qui s'ensieut à haulte voix, tout en plorant: »Priez pour l'ame du très excellant, très puissant et très victorieux prince le Roy Charles, $V I{ }^{e}$ de ce nom. "Et lors cedit herault print sa mace en la main, et s'arriva contre le corps en la fosse. Pensez qu'il n'y eut sy bon cour qui ne plorast. Puis, apprez [l'espace de temps] que l'on pooit achever ung patenostre, il tira sa mace, les armes devers le hault, et cria: »Vive le Roy! « et secretaires se mirent à crier: »Vive le Roy Loys! « (Mathieu d'Escouchy, Chronique, Bd. II, S. 443 f.). Nachtwache, Ehrenplatz und Schlüsselrolle während der Beerdigungszeremonie finden sich in gleicher Weise z.B. auch bei den Obsequien Philipps des Guten von Burgund, vgl. Georges Chastellain, Euvres, Bd. V, S. 235; Jacques de Clercq, Mémoires, Bd. IV, S. 304 sowie LORY, Les obsèques, S. 35.

27 Vgl. z. B. den Einritt der französischen Gesandtschaft in Arras 1435, Enguerran de Monstrelet, Chronique, Bd. IV, S. 135.

28 Zur Rolle z.B. des Wappenkönigs Toison d'or bei den Festen des gleichnamigen Ritterordens vgl. De Gruben, Chapitres de la Toison d'or, passim.

29 Vgl. z. B. die Darstellung des Olivier de La Marche, Mémoires, Bd. II, S. 367.

30 Eine Ausnahme bildet der eben genannte Toison d'or, der bei den Ordensfesten nicht nur eine wichtige Rolle während des Zeremoniells übernahm, sondern auch mit deren Organisation betraut war, vgl. Olivier de La Marche, Mémoires, Bd. IV, S. 167 (»Epistre pour tenir et celebrer la noble feste du Thoison d'Or «). Daß es sich hierbei um eine Ausnahme handelt, zeigt das Beispiel des französischen Michaelsordens. Hier wurde 1476 zusätzlich zu den bestehenden Ämtern, unter anderem jenes des Ordensherolds, das eines prévôt-maître des cérémonies eingeführt, vgl. Ordonnances des rois, Bd. XVIII, S. 217-223. Doch scheint zumindest im beginnenden 14. Jahrhundert in England den Heroldskönigen auch in der Organisation von Festen eine gewichtige Rolle zugekommen zu sein, was sich möglicherweise aus ihrer gleichzeitigen Funktion als Könige der Spielleute erklären mag, denen genau dies oblag. Vgl. hierzu Clouzot, Roi des ménestrels.

31 Zu den Wappenmarken vgl. u. a. NEUBECKER, Heraldik, S. 20. Eine zeitgenössische Beschreibung der Wappenmarken und ihrer Geschichte, wie sie von den Herolden selbst verbürgt wurde, findet sich bei Antoine de La Sale, Le traité, S. 300 f. Zu den Wappenkönigen allgemein vgl. jüngst Stevenson, The Scottish King of Arms, und Simonneau, Le roi d'armes. 
wurden. Zumindest nominell befanden diese sich noch in der Ausbildung 32 . Aber auch ihnen wurde bei der Aufnahme in den Dienst eines Herren ein Amtsname verliehen, der oft dessen Devise oder Motto entsprach ${ }^{33}$. Zu ihrer Ausbildung wurden sie für mehrere Jahre durch Europa geschickt, um die Höfe, deren Adel und Wappen kennenzulernen ${ }^{34}$.

Die feste Einbindung in ein Dienstverhältnis, der stark erweiterte Aufgabenbereich, die Herausbildung einer internen Hierarchie, die zunehmende Organisation einer spezifischen Ausbildung: All dies läßt sich als die Geschichte einer zunehmenden Institutionalisierung lesen, die ihren Höhepunkt 1407 im Versuch der Gründung einer landesweiten Vereinigung der französischen Herolde und deren gemeinsamem Auftreten im Rahmen mehrerer Suppliken an den König fand. Doch ist aufgrund fehlender Forschungen hierzu kaum etwas bekannt.

Sicher ist zumindest, daß die Herolde in der Kirche Saint-Antoine-le-Petit ${ }^{35}$ eine gemeinsame Kappelle besaßen. Dies wird unter anderem aus einem kurzen

32 Die tatsächliche Bedeutung des Begriffes ist noch immer unklar. Einerseits könnte es sich auch hier, ähnlich wie bei dem Begriff »roi d'armes« (siehe unten, S. 26), um eine Verkürzung z. B. aus der möglichen Bezeichnung "poursuivant des hérauts d'armes « handeln, begleiteten die Persevanten während ihrer Ausbildung doch sicher die Herolde, v. a. aber folgten sie diesen in ihren Ämtern nach. Das Wort »poursuivant « selbst kann neben Verfolger, Nachfolger auch im Sinne von »candidat « (Kandidat, Anwärter) oder »prétendant « (Prätendent, Bewerber) verstanden werden, vgl. Godefroy, Dictionnaire, Bd. X, S. 394, sowie Huguet, Dictionnaire, Bd. VI, S. 122. Andererseits beschränkt sich die Bezeichnung nicht allein auf Auszubildende. So wurden auch die $>$ Herolde $<$ kleinerer Herren meist als Persevanten bezeichnet und am Hof der Herzöge von Burgund dienten einige in dieser Funktion über Jahrzehnte hinweg. So könnte die Bezeichnung gleichzeitig auch auf den Umstand Bezug nehmen, daß die Persevanten den Taten der Ritterschaft nachfolgten, den Wappen und faits d'armes.

33 Dies konnten Namen sein wie Fusil (Persevant des Herzogs von Burgund), Cerf Volant (Persevant des Königs Karl VII.) oder auch Ma Vie und Ainsi le vueil (beide im Dienste des Herzogs der Bretagne). Zahlreiche Beispiele für die Benennung von Persevanten, aber auch von Herolden nach der Devise oder dem Motto ihres Herrn hat zusammengetragen: HABLOT, La devise. Beispiele aus den burgundischen Quellen finden sich zahlreich im Ämterkatalog der Datenbank »Heraudica «.

34 Vgl. hierzu den Geleitbrief, welchen der französische König Karl VI. König Ferdinand I. von Aragon bezüglich seines Persevanten Jamais schrieb, ediert bei VIELLARD, AvEzou, Lettres originales, S. 358-360, siehe auch noch unten, S. 30.

35 Die Kirche existiert heute nicht mehr. Sie befand sich auf der Rue François-Miron (Hausnr. 82), bzw. der Rue du Roi-de-Sicile (Hausnr. 13) im 3. Arrondissement in Paris. Es handelt sich dabei um ein ehemaliges Hospiz des Augustinerordens, das von Karl V. stark gefördert wurde. 1361 wurde es vom Abt auch als Haus eingerichtet. Baubeginn der Kirche war 1368. Das Hospiz wurde 1617 aufgehoben und in ein Seminar verwandelt. Germain Brice berichtet 1753, daß Saint-Antoine-le-Petit im Jahre 1707 durch einen Brand großen Schaden erlitt. Seit 1777 endgültig geschlossen, wurde es 1804 abgerissen. Vgl. HiLlaireT, Dictionnaire Historique, Bd. I, S. 547 und BRICE, Description de la ville, Bd. II, S. 169. Der einzige Hinweis, der über die Gründungsurkunde hinaus auf mögliche Aktivitäten der Herolde in der Kirche Saint-Antoine-le-Petit verweist, ist die Bestattung des Wappenkönigs von Navarra an eben diesem Ort. Sein Epitaph ist abgedruckt in Épitaphier du vieux Paris, Bd. I, S. 119, Nr. 191. Für nähere Informationen siehe NARBONA, L'origine de l'office d'armes, S. 636-640. Inès Villela-Petit bringt in einem Beitrag zur Kirche Saint-Antoine-le-Petit 
Abschnitt im Wappenbuch des Gilles Le Bouvier deutlich, der Karl VII. als Herold Berry diente, in dem er festlegt, daß dieses nach seinem Tode entweder in die Hände seiner Erben oder der Geistlichen von Saint-Antoine-le-Petit zu übergeben $\operatorname{sei}^{36}$.

Die Dokumente zur Gründung der Kapelle der französischen Herolde in der Kirche Saint-Antoine-le-Petit in Paris und eine dazugehörige Ordonnanz über die gemeinsame Betreibung und damit ganz allgemein die Vereinigung der französischen Herolde sind jedoch nur in dem einzigen bisher edierten Heroldskompendium überliefert. Eine breitere Überlieferung fanden hingegen die Suppliken der Herolde aus dem Jahre 1408, deren Abfassung in der Gründungsurkunde vereinbart wurde (im Gegensatz zu einer weiteren Bittschrift, die 1435 anläßlich der Friedensverhandlungen in Arras entstand und ebenfalls nur in einem Kompendium enthalten ist) $)^{37}$.

Aus der Gründungsvereinbarung wird dabei deutlich, daß diese mit dem Ziele unternommen wurde, die französischen Herolde in einer Art Zunft zu organisieren. Den hier zusammengeschlossenen Herolden sollte eine Mitbestimmung bei der Ernennung neuer Herolde und Wappenkönige zukommen. Und jene, welche ohne Einverständnis ihrer Kollegen ihre Ämter erhielten, sollten fortan von gemeinsamen Einkünften ausgeschlossen werden. Zugleich wurden klare Normen festgesetzt, welche Voraussetzungen für die Aufnahme in das office d'armes gelten sollten und welche Ausbildung ein poursuivant zu durchlaufen habe, bevor er zu einem Herold ernannt werden könne. Der Zugang zum Heroldsamt sollte somit limitiert, dieses selbst strikten Regeln unterworfen werden.

Die Gründe für dieses Engagement treten in den Suppliken deutlich hervor. Den gleichen Forderungen geht hier nämlich die Beschwerde voran, daß durch einfache Ritter und capitaines eine große Zahl von altersschwachen Spielleuten, von Glücksspielern, Trunkenbolden und anderen Unholden zu Persevanten ernannt würden, ohne daß sie hierzu überhaupt berechtigt seien. Andere würden gar zu Herolden ernannt, ohne daß sie von diesem Amt nur das Geringste verstünden. Sie machten dem office d'armes, ihren Herren und dem ganzen Adel dabei nichts als Schande ${ }^{38}$.

zudem ein Altarbild aus der Kirche mit den Herolden in Verbindung, doch ist ihre allein auf Spekulationen aufbauende Zuweisung bei näherem Hinschauen kaum haltbar, vgl. VILLELAPETIT, Souvenir d'un retable.

${ }^{36}$ Et après mon décèps sera mis icellui livre ès mains de mes héritiers, ou à saint Antoine le Petit à Paris en la main et garde des religieux de séans, affin que lesdits nobles le treuvent $s$ 'ils en ont affaire, et pareillement ceux dont les dictes armes son audit livre paintes (VALLET DE VIRIVILle [Hg.], Armorial de France, S. 40).

37 Vgl. Roland (Hg.), Parties inédites. Die Dokumente zur Gründung von Saint-Antoine-lePetit finden sich auf S. 99-107, die Suppliken S. 107-127.

38 Premièrement, pour ce qu'il est vray que plusieurs nobles par cy-devant ont fait pluiseurs poursievans de vielz ménestrelz qui ne pooient plus corner, et qui ne se pooient aidier ne servir en l'office d'armes; pluiseurs aultres chevalliers en ont fait de joueurs de batteaulx et d'aultres gens qui font mestier infâmes et reprochiés en tesmoignage de vérité, au grant vitupère et déshonneur del office et desditz supplians, et tout le contraire de ce qui al office appartient, ce qu'ilz, ne peuvent ne doibvent faire par raison. [...] Item, que pluiseurs poursie- 
Jene Herolde also, die sich in der Vereinigung von Saint-Antoine-le-Petit zusammenschlossen, wollten sich auf diesem Wege deutlich von einem inferioren Milieu abgrenzen bzw. dieses von ihrem Amt ausschließen. Inwieweit diese Vereinigung Bestand hatte, und inwieweit die Supplikanten von 1408 auch vom König erhört wurden, dessen Unterstützung sie für ihr Anliegen dringend bedurften, ist unbekannt. Da sich aber eine größere Gruppe von Herolden ganze dreißig Jahre später ein weiteres Mal genötigt sah, sich an Fürsten und Adel zu wenden, um den wilden Ernennungen kleinerer Herren Einhalt zu gebieten, scheint ihr Bemühen wohl ohne großen Erfolg geblieben zu sein. Die nächsten Dokumente, welche über die Ordnung des französischen Heroldswesens Auskunft geben, sind erst wieder aus dem Jahre 1487 bekannt, als das Chaos der ersten Jahrhunderthälfte schon längst verklungen war ${ }^{39}$. Und erst 1495 haben sich in Burgund Olivier de La Marche und andere auf Anweisung Philipps des Schönen hin offiziell mit den Privilegien der Herolde auseinandergesetzt ${ }^{40}$. Was die Heroldsvereinigung von Saint-Antoine-le-Petit anbelangt, so sei hier auf eine weitere, im Rahmen der vorliegenden Arbeit neu entdeckte Supplik verwiesen, in der es heißt, daß die Herolde all ihre diesbezüglichen Dokumente alsbald in den Wirren des Krieges wieder verloren hätten ${ }^{41}$.

Um von der Situation der französisch-burgundischen Herolde im ausgehenden 14. und dem 15. Jahrhundert ein genaueres Bild zu erhalten, wäre ein besseres Verständnis vor allem ihrer sozialen Herkunft wie ihrer gesellschaftlichen Stellung vonnöten. Die meisten Darstellungen zum Heroldswesen begnügen sich jedoch mit einem einfachen Verweis auf die Wurzeln der Herolde im Milieu der Fahrenden und Unterhalter, von denen sich diese - ob ihrer zunehmenden Spezialisierung und Institutionalisierung - im Verlaufe des 14. Jahrhunderts allmählich

vans non souffisans, non habilles et non sachans ès fais et ès mérites dudit office, se mettent et font mettre de fait par puissance de seigneurs, ou par prières et requestes d'aulcuns à qui il n'en chault del office, ou qui riens n'en scevent ou aultrement en office de hérault; les aulcuns, ainschois qu'ilz soient poursievans et en office de roy d'armes, ainschois qu'ilz soient héraulx, qui est au très-grant vitupère de ceulx qui les font et dont ilz portent les noms, au déshonneur, blasme et préjudice del office et desdis supplians (ibid., S. 108f.).

39 Vgl. die Ordonnanz des Johann von Bourbon, Konnetabel von Frankreich, zur Immunität der französischen Herolde (London, BL, Lansd. 285, fol. 206-208) sowie die Ernennungsurkunde Karls VIII. für Gilbert Chauveau, genannt Bourbon, zum Wappenmarschall der François, mit dem Auftrag, ein Wappenbuch aller französischen Adeligen zu erstellen (Paris, BnF, Clairambault, 902, fol. 30r-32r und Paris, BnF, n.a. fr., 7243, fol. 176r-179v). Vorbild für letzteren war sehr wahrscheinlich das Wappenbuch des Guillaume Revel, der ebenfalls in bourbonischen Diensten stand, siehe unten, S. 42. Eine sehr eingeschränkte Wahrnehmung der Herolde durch das französische Königtum konstatierte bereits Philippe Contamine, Office d'armes, S. 321, der dabei zugleich auf die mediokre soziale Stellung der Herolde verweist.

$40 \mathrm{Vgl}$. SimONNEAU, Le roi d'armes, mit einer Edition des Textes.

41 Item, et de toutes et chacunes choses dessusdittes lesdits officiers d'armes avoient lettres des roiz de France et autres princes en leur chapelle a Sainct Anthoine a Paris, lesquelles ont esté perdues pour les guerres. Et en oultre avoient autres lettres et enseignemens de la fondacion de ladicte chappelle qui pareillement ont esté perdues (Paris, BnF, fr. 1983, fol. 47r). 
etablierten ${ }^{42}$. Für die Situation der Herolde im 15. Jahrhundert, soweit überhaupt erwähnt, bleibt es dann bei dem Hinweis, daß diese sich wohl noch immer aus Nichtadligen rekrutierten, aber sicherlich einen gewissen Stand und ein gewisses Ansehen genossen, da ihr Amt - und hier stützt man sich meist auf die Aussagen der Heroldskompendien selbst - ja spezielle Fähigkeiten und Kenntnisse voraussetzte. $\mathrm{Da} ß$ dies nicht allgemein gelten kann, darauf verwies unter dem Eindruck der ebenfalls in den Heroldskompendien enthaltenen Suppliken bisher allein Philippe Contamine, der damit zum ersten Mal überhaupt die Frage nach der sozialen Stellung der Herolde im 15. Jahrhundert formulierte ${ }^{43}$.

\subsubsection{Soziale Herkunft und gesellschaftlicher Stand der Herolde}

Seit dem Ende des 14. Jahrhunderts scheint es, daß die Herolde geradezu zu einem Massenphänomen wurden. So waren mit den Delegationen der Franzosen, Engländer und Burgunder zu den Verhandlungen von Arras im Jahre 1435 mehr als 130 Vertreter des office d'armes angereist ${ }^{44}$. Die Zahl der am burgundischen Hof in einem festen Dienstverhältnis stehenden Herolde belief sich unter Philipp dem Guten und Karl dem Kühnen durchschnittlich auf 10 bis $20^{45}$, neben denen in der recette générale des Herzogs jährlich nochmals bis zu 38 weitere Herolde und Persevanten fremder Herren erscheinen konnten ${ }^{46}$. Dabei stammten diese nicht allein aus Burgund oder Frankreich. Das Heroldswesen war vielmehr ein ausgeprägt internationales Phänomen. Herolde gab es ebenso in Portugal, Spanien oder Italien, wie in England, im Reich, in Ungarn, Dänemark, Schottland, Polen oder auch in Litauen ${ }^{47}$. Zudem war die Anstellung von Herolden nicht allein auf den Adel beschränkt. Einerseits besaßen auch Städte wie Tournai, Lille, Brügge oder

42 Vgl. v. a. Wagner, Heralds of England, S. 27-34 oder auch KeEn, Chivalry, S. 77.

43 Vgl. mit zahlreichen Belegen ConTAMINE, Office d'armes.

44 Contamine, Aperçus nouveaux, S. 593-596, gibt eine Liste der Herolde, deren Anwesenheit in Arras durch verschiedene Texte belegt ist. Bei der Krönung König Wenzels 1376 in Aachen wurde die Zahl der anwesenden Herolde in den Rechnungen mit 40 angegeben (Kůininxbergh Goetkin ind Vleckestein mit allen ieren gesellen hiralden der 40 wären 15 gulden $52^{1 / 2} 2 \mathrm{mk}$., Deutsche Reichstagsakten. Ältere Reihe, Bd. I, S. 169f.). Und Eberhard Windecke gibt für den Ofener Hoftag von 1412 an, der u. a. auch von den Königen von Polen und Bosnien und zahlreichen weiteren Fürsten und Herren besucht wurde, daß hier insgesamt 298 herolt und bersefant anwesend waren, vgl. AltManN (Hg.), Eberhard Windeckes Denkwürdigkeiten, S. 12. Doch ist nicht auszuschließen, daß Eberhard Windecke in diese Zahl auch alle anwesenden Spielleute mit einschließt.

45 Für Philipp den Guten vgl. z. B. KruSE, Paravicini (Hg.), Hofordnungen, Nr. 16, §§ 554573, für Karl den Kühnen Hiltmann, Paravicini (Hg.), Hofordnungen, Nr. 5, §§ 847-869. 46 Vgl. Thuret, Officiers d'armes, S. 49, sowie zuletzt Hiltmann, Herolde, S. 50-57.

47 Zu Frankreich, England, Schottland, Portugal, Aragon, Kastilien, Navarra, Florenz, Dänemark, Polen usw. vgl. die verschiedenen in der Bibliographie aufgeführten Titel sowie deren verschiedene Belege in der Datenbank »Heraudica «. Zu einem Herold des Ladislaus I. (Postumus) von Ungarn, den dieser 1443 mit einer Herausforderung zum Großtürken schickt, vgl. RÖMHELD, Die diplomatischen Funktionen, S. 91 m. Anm. 145 f. Zur mehrfachen Nennung eines Lutzke, Herold Witolds von Litauen, im Marienburger Tresslerbuch vgl. Boockmann, Spielleute und Gaukler, S. 223 m. Anm. 49. 
Valenciennes, aber auch Paris oder Bourdeaux eigene Stadtherolde ${ }^{48}$. Andererseits waren sie auch im Dienste geistlicher Herren wie der Bischöfe von Nantes, Lüttich oder Köln oder eines Kardinals de Orsini anzutreffen ${ }^{49}$.

Unter diesen Herolden sind nun mehrere bekannt, von denen sich ohne weiteres behaupten läßt, daß sie, wohlhabend und etabliert, den sozialen Aufstieg geschafft haben. Für einen gewissen Johannes Sper, rex heraldorum comitatus Artesie, also den Wappenkönig von Artois, ist aus dem Jahre 1388 eine Bestätigung seiner Nobilitierung durch Karl VI. überliefert - als Anerkennung für dessen langjährige Dienste ${ }^{50}$. Ein Jahrzehnt früher (1375) wurde bereits Giles Merlot, der Herold des Bertrand du Guesclin geadelt, der später im Vertrag über die Gründung der Kapelle von Saint-Antoine-le-Petit allen anderen Herolden Frankreichs als roy d'armes des François voransteht ${ }^{51}$. Aber auch am Ende des 15. Jahrhunderts wurden Herolde in den Adelsstand erhoben. So ist unter anderem von einem Robert du Boullay, Herold Marie des Königs Karl VIII. bekannt, daß er seinen Herrn 1494/95 auf dessen Kriegszug nach Neapel begleitete und von diesem dort seine lettres d'annoblissement erhielt, an denen er sich jedoch nicht lang erfreuen konnte, verstarb er doch kurz darauf auf seinem Rückweg nach Frankreich ${ }^{52}$. Obgleich sich für das 15. Jahrhundert noch keine allgemeine Tendenz ausmachen läßt, so scheint es zumindest wahrscheinlich, daß derlei Nobilitierungen von Herolden verstärkt erst im 16. Jahrhundert auftraten, wo sie des öfteren nun auch den Titel eines Schildknappen (écuyer) führen ${ }^{53}$.

48 Die Stadtherolde Tournai (Tournai), Francque Vie (Valenciennes), Epinette (Lille) sind wie der Persevant Ours (Brügge) sowohl in den Rechnungsbüchern des Herzogs von Burgund (Heraudica, sources, $\mathrm{n}^{\text {os }} 11437,11351,11313$ und 13024) als auch in denen verschiedener flandrischer Städte belegt (VAN DEN NESTE, Tournois, Nr. 69, 128, 133, 139, 210, 218 , usw.). Ein Pariser Stadtherold ist für die Jahre 1431 und 1461 erwähnt (GuENÉE [Hg.], Les entrées royales, S. 64 f., 87; Jean de Roye, Journal, Bd. I, S. 24 f., gibt als dessen Amtsnamen Loyal Coeur). Ein Stadtherold von Bordeaux ist in den Rechnungen der Stadt mindestens für das Jahr 1501/02 enthalten: Item, plus compte qu'ed a pagat a Bernard de Serres, heraud de la present villa, la soma de vingt cinq livras bord., et asso per sons gatges ordinaris d'aquest premey 1/2 an per estar heyraud de la villa per sso.... xxv l. s. d. (DuCAUNNÉs-Duval [Hg.], Comptes des recettes, S. 88). Zur Frage der Stadtherolde am Beispiel der burgundischen Niederlande vgl. ausführlich ViLTART, Simonneau, City Heralds.

49 Zum Persevanten des Bischofs von Nantes vgl. Jones, Vers une prosopographie des hérauts, S. 1426. Ein Persevant des Arnoldus von Hoern, Bischof von Lüttich, erscheint zwischen 1387 und 1388/89 in den Rechnungen des Herzogs von Geldern (vgl. NIJSTEN, Het hof van Gelre, S. 131 m. Anm. 13), ein Ardsbergh, Persevant des Erzbischofs von Köln, ist dort ein Jahr später genannt (vgl. ibid., Beilage XII und 153 m. Anm. 108). Des cardinal de Ursinis persefant ist in den Kosten der Stadt Nürnberg zum Reichstag im Mai 1426 überliefert (vgl. Deutsche Reichstagsakten. Ältere Reihe, Bd. VIII, S. 500).

50 Vgl. DouËT D’ARCQ (Hg.), Choix de pièces, Bd. I, S. 88-90.

51 Egidius Mellot, nuncius nostri, heraudus dilecti et fidelis consiliarii et constabularii nostri Bertrandi du Guesclin, Paris, An, JJ, Reg. 106, ch. 215. Ich danke Michael Jones (Nottingham) für diesen Hinweis.

52 Vgl. Le Page, Notice, S. 39, sowie S. 47 f., mit der entsprechenden Confirmation de noblesse für dessen Enkel, den lothringischen Herold Emond du Boullay aus dem Jahre 1543. 53 Vgl. u. a. Jehan le Forestier, escuier, herault d'armes du nom et tiltre Bourgoigne, dessen Bericht über eine ihm anvertraute Mission nach Cambrai aus dem Jahre 1534 erhalten ist 
Ein weiterer Beleg für den sozialen Aufstieg einiger der Herolde ist mit dem Testament des Jean Piat aus dem Jahre 1413 überliefert, welcher als Herold Genève im Dienste des Amadeus VIII. von Savoyen stand ${ }^{54}$. Nichtadeliger Herkunft, wohnte er in Yverdon-les-Bains (Kt. Waadt), wo er jedoch keinen herausgehobenen Status genoß und seine Familie das Bürgerrecht erst im Laufe des 15. Jahrhunderts erhielt. Somit weder Adliger noch Bürger, entspricht sein Testament dennoch dem eines zu Reichtum gekommenen Bürgers, selbst dem eines einfachen Adligen. In seinem letzten Willen bestimmte er unter anderem, daß er in der Abteikirche von Montheron (Kt. Waadt) in der dem Hl. Antonius geweihten Seitenkapelle vor dem Altar zu bestatten sei, wo er bereits ein Grab vorbereitet habe, in welches ihm später auch sein Sohn folgen solle. Mit anderen Worten: Er wollte sich außerhalb seiner eigenen Pfarrkirche in einem Kloster bestatten lassen, wo er vor einem Seitenaltar eine Familiengrablege plante und errichten ließ.

Und natürlich ist hier als Wappenkönig Toison d'or auch der berühmte Jean Lefèvre, Seigneur de Saint-Rémy zu nennen ${ }^{55}$. Dieser stammt aus der Stadt Abbeville, in deren Registern er noch bis ins Jahr 1437 ganz einfach unter dem Namen Jean Lefèvre verzeichnet ist. Erst ab diesem Moment läßt er seinen eigentlichen Namen weg und nennt sich fortan meist nur noch Seigneur de Saint-Rémy (de la Vacquerie, Avesnes und Morienne). Aber all diese Besitzungen und Rechte, und damit auch den Adelsrang, mit dem sich Jean Lefèvre gern schmückte, brachte ihm erst die günstige Heirat mit der Marguerite de Pierrecourt ein ${ }^{56} . \mathrm{Zu}$ diesem Zeitpunkt nahm er aber bereits seit einigen Jahren - als Wappenkönig Toison d'or - eine privilegierte wie führende Stellung unter den Herolden des burgundischen Herzogs ein, mit dem ihn wohl auch eine engere persönliche Beziehung verband. Sicher bereits vor dessen Zeit als Herzog stand er unter dem Namen Charolais im Dienste Philipps des Guten, von dem er nach der Gründung des Ordens vom Goldenen Vlies im Jahre 1431 zu dessen Wappenkönig ernannt wurde, in welcher Funktion er dann für über 37 Jahre verblieb. Nach dem Tode seines Herrn im Jahre 1467 und angesichts seines mittlerweile auch eigenen hohen Alters entsagte er Pfingsten 1468 seinem Amt und wurde im gleichen Atemzug durch Karl den Kühnen zum Ritter geschlagen. Unter allen burgundischen Herolden bleibt er zu seiner Zeit jedoch der einzige, von dem bekannt ist, daß er vom Herzog eine stattliche Jahrespension für seinen Unterhalt bezog 57 .

Bei alledem bleibt zu beachten, daß es bezüglich der sozialen Stellung der Herolde auch regionale Unterschiede geben konnte. So ist zum Beispiel von den

(Paris, BnF, fr. 5240, fol. 96). Oder auch Louis de Perreau, Autor des »Discours de l'origine, office, charge, progrès, privileges et immunitez des roys et herauts d'armes de France« aus dem Jahre 1533, der sich selbst als chevalier, seigneur de Castillon, de Tremar et de l'Espinay, herault d'armes bezeichnet (Paris, Arsenal, 5129, fol. 2-53v, hier fol. 8r). Er war Herold im Amt des Mont-Saint-Michel, in welchem er einem gewissen Tavard, écuyer, nachfolgte (vgl. BoudREAU, Traités de blason, Bd. III, S. 786).

$54 \mathrm{Vgl}$. Rouiller, Les habits du héraut.

$55 \mathrm{Zu}$ dessen Biographie am ausführlichsten Morand (Hg.), Chronique, Bd. I, S. i-lxiii.

56 Ibid., S. xii.

57 ThuREt, Officiers d'armes, S. 113. 
Herolden des Herzogs der Bretagne bekannt, daß mehrere von ihnen einem kleinadeligen oder gutbürgerlichen Milieu entstammten und bisweilen auch kleinere Herrschaften innehatten. Die Wappenkönige unter ihnen erhielten zumeist eine beachtliche Jahrespension und hatten es zu ansehnlichem Wohlstand gebracht ${ }^{58}$.

Bei all den genannten Herolden jedoch, denen ein sozialer Aufstieg gelungen ist oder die sich gar schon aus besseren Verhältnissen rekrutierten, handelte es sich fast ausschließlich um Wappenkönige im fürstlichen Dienst. Daneben gab es aber auch jene Vertreter ihres Amtes, die den arrivierten Herolden Anlaß zur Klage gaben - die Persevanten einfacher Herren, Ritter und capitains. Auch deren Spuren lassen sich in den Quellen finden. Und schon in Anbetracht der Stellung ihrer eigenen Herren konnten sie niemals zu einer auch nur annähernd vergleichbaren Stellung wie ihre Kollegen an den Fürstenhöfen gelangen.

Bei ihren Herren konnte es sich um herausgehobene Persönlichkeiten wie den burgundischen Kanzler Nicolas Rolin oder den burgundischen Marschall Thibaut de Neufchâtel handeln, aber auch um weniger bedeutende Zeitgenossen ${ }^{59}$. So berichtet zum Beispiel Enguerran de Monstrelet anläßlich des Todes des englischen Königs Heinrich V. im Jahre 1422 eine kurze Episode um einen alten pikardischen Ritter namens Sarasin d'Ailly und seinen ebenso betagten Persevanten Havrenas (Havernast) ${ }^{60}$. Ein andermal ist uns der Geleitbrief eines Iean de Rouuerel, Cheualier, seigneur dudict lieu überliefert, den dieser 1429 seinem Persevanten Regnaut Talmas ausstellte ${ }^{61}$. Es ist wohl davon auszugehen, daß es sich bei diesen Belegen um keine Einzelfälle handelt, die Indienstnahme von Persevanten auch bei kleineren Herren zu dieser Zeit vielmehr der Regel entsprach.

Allem Anschein nach gab es also kein einheitliches Milieu der Herolde. Mit den großen Wappenkönigen und Herolden im fürstlichen Dienste auf der einen und den zumeist als Persevanten bezeichneten Herolden kleinerer Herren auf der anderen Seite waren sie vielmehr in zwei Gruppen unterteilt. Dabei ist letztere geradezu dazu prädestiniert, noch weitaus engere Beziehungen zum Milieu der Fahrenden zu unterhalten, aus dem ihre arrivierten Kollegen das office d'armes gerade zu etablieren suchten ${ }^{62}$. Doch auch deren Beziehung zu den Spielleuten

\footnotetext{
58 JONES, Vers une prosopographie des hérauts, S. 1412-1415.

${ }^{59}$ Für zahlreiche Beispiele von Persevanten im Dienste burgundischer Herren vgl. Heraudica, offices, ${ }^{\text {os }} 0145$ (seigneur de Longueval), 0390 (seigneur de Rambures), 0477 (Louis de la Viefville de Sains) u. a. Eine Übersicht über die Herolde bretonischer Herren findet sich bei JONES, Vers une prosopographie des hérauts, S. 1426. Für eine umfassende Prosopographie der Herolde englischer Adeliger vgl. CokAYne, The Complete Peerage, Bd. XI, Appendix C, S. 39-104.

$60 \mathrm{Vgl}$. Enguerran de Monstrelet, La Chronique, Bd. IV, S. 116f. Siehe hierzu noch unten, S. 36. Zu Mathieu, seigneur d'Ailly du Quesnoy-les-Airaines, Acheu et d'Havernast, genannt Sarasin, vgl. Belleval (Hg.), Nobiliaire de Ponthieu, Bd. II, S. 6.

$61 \mathrm{Vgl}$. Belleforest, Les Grandes Annales, Bd. I, fol. 760r.

62 Zum Versuch, sich in eine Abstammung aus der Ritterschaft einzuschreiben, gar die Grenze zwischen Heroldswesen und Ritterschaft aufzulösen, noch ausführlicher bei der Analyse des »Selon les dits-Traktates« und des »Montjoye-Traktates « unten, Kap. 4.1. Vgl. hierzu auch die Supplik des Wappenkönigs Garter an den englischen König, in welcher er
} 
war bei weitem enger ${ }^{63}$. Die Herauslösung des Heroldsamtes, zumindest aus der funktionalen Gruppe der Spielleute, ging viel langsamer vonstatten als bisher angenommen und war wohl selbst am Ende des 15. Jahrhunderts noch lang nicht abgeschlossen.

Auch wenn mit dem Beginn des 14. Jahrhunderts die allmähliche Institutionalisierung des Heroldswesens begann, auch wenn die Herolde zunehmend spezifische Aufgaben übernahmen, welche sie deutlich von den anderen Spielleuten abgrenzten, so wurde doch noch bis weit in das 14. Jahrhundert hinein zwischen beiden nicht unterschieden. Im »Perceforest«, der zwischen 1337 und 1344 entstand, tauchen sie immer wieder gemeinsam auf, wobei sie völlig indifferent auch für typische Aufgaben der Herolde genannt werden:

Adont fist [le roy] mander pardevant luy heraulx et menestrelz et leur commanda qu'ilz alassent nuncier par tout le royaume d'Angleterre et d'Escoce et des ysles voisines que tous gentilz hommes qui aiment loz et pris et toutes dames et damoiselles d'honneur fussent au Noeuf Chastel en Bretaigne au derrain jour de may ${ }^{64}$.

Ähnliches findet sich im »Restor du Paon«, den Jean Le Court in der gleichen Zeit verfaßte ${ }^{65}$. Deutlicher wird dieser Umstand noch in den Rechnungsbüchern der Höfe und Städte des 14. Jahrhunderts, wobei ein Großteil der folgenden Beispiele - dies sei einschränkend hinzugefügt - zumeist aus dem besser erforschten niederrheinischen Raum stammt.

In den Rechnungen des Grafen von Holland erscheint 1358/59 zum Beispiel ein gewisser Jan Dyllen, der unter anderem auch als Verfasser der allegorischen »Klage der Tugenden « bekannt ist ${ }^{66}$, als Jan Dyllen den yraut, die voer mijns heren tafel sprac ${ }^{67}$. Am Hof Wilhelms I., des Herzogs von Geldern, ist für 1389 ein Guldentonge, heralt belegt, der drei Jahre später erneut hier erscheint, nun aber

die Trennung des Heroldsamtes von den Spielleuten in den regelmäßigen largesses fordert, vgl. WAGNER, Heralds of England, S. $48 \mathrm{f}$.

${ }^{63}$ In der bisherigen Forschung wurde zumeist von einer Etablierung der Herolde von ihrem ursprünglichen Milieu der Fahrenden und Unterhalter gesprochen. So meint z. B. LESTER, Literary Activity, S. 225, daß die Herolde ihre Rolle als Verbreiter von Ruhm und Ehre allmählich von ihren >alten Rivalen<, den Spielleuten, übernommen hätten. Vielmehr aber scheint es sich funktional wie institutionell um eine konstant enge Bindung zwischen beiden Gruppen gehandelt zu haben. Derlei Zusammenhänge und Kontinuitäten wurden bisher jedoch allein für den deutschen Bereich (PETERs, Herolde und Sprecher, S. 247 und 249f.) beschrieben und zumindest von Wim van Anrooij als eine spezifisch deutsche Entwicklungsgeschichte gesehen, was jedoch noch zu prüfen ist (vAN ANROOIJ, Spiegel van ridderschap, S. 50-53). Auf eine funktionale Kontinuität macht Maurice Keen aufmerksam, wenn er schreibt, daß die frühe Verbindung mit den Spielleuten die Herolde zu einer Literatengruppe gemacht und daß ihre spätere Rolle als Chronisten tapferer Taten den Bestand dieser literarischen Bildung gewährleistet hätte, vgl. KeEN, Chivalry, S. 139.

64 Roussineau, Perceforest, Bd. I, S. 269, Kap. 477, Z. $2-8$.

65 Vgl. Jean Le Court, dit Brisebare, Le Restor du Paon, S. 117-119, Kap. 39 und 40.

66 Vgl. BRANDIS, Minnereden, Nr. 443.

67 Vgl. Jonckbloet, Geschiedenis, S. 598. Vgl. auch Pietzsch, Fürsten und fürstliche Musiker, S. 166 (mit anderen Rechnungseinträgen zum Vergleich). 
als spreker qualifiziert wird ${ }^{68}$. Im Jahre 1400 wird in Douai, gemäß den Rechnungsbüchern der Stadt, ein in Laon stattfindendes Turnier durch einen Raulin, trompette, herault angekündigt ${ }^{69}$. Und 1401 ist in den Rechnungen der Johanna I. von Brabant ein Claesken den heeraut, piper genannt ${ }^{70}$.

Einige der Herolde wurden in dieser Zeit noch immer als roys des hérauts erwähnt - eine Amtsbezeichnung, die wohl erst zu Beginn des 15. Jahrhunderts durch die des roy d'armes ersetzt wurde. Doch ist auch dieser neue, pretentiöse Titel, der seinen Inhaber als König der Wappen (und Waffen) bezeichnet und ihm damit geradezu die Hoheit über diese anträgt, wohl nicht anders denn als einfache Verkürzung aus dem ursprünglichen roy des hérauts (d'armes) ${ }^{71} \mathrm{zu}$ verstehen. Dieser wiederum wurde noch lange synonym mit roy des menestrels gebraucht ${ }^{72}$ und hatte auch keine andere Bedeutung als letztgenannter Titel oder der eines roy des ribauds (Bubenkönig): die Aufsicht über und die Verantwortung für eine bestimmte soziale Gruppe bzw. Berufsgruppe ${ }^{73}$. Somit war der Wappenkönig einer marche wohl weniger der Herr über die Wappen dieser Wappenmark. Vielmehr übte er die Oberaufsicht über die Geschäfte der Herolde innerhalb seines Amtsbereiches aus ${ }^{74}$.

Die Verquickung von Herolden und Spielleuten erscheint aber nicht nur in den Rechnungsbüchern oberrheinischer Fürsten und flandrischer Städte. Auch beim französischen König finden sich hierfür Belege. So lautet ein Eintrag aus dem Jahre 1381 unter der Rubrik »Dons «: Le roy des héraulx et les autres héraulx et menesterelx du duc Aubert, qui ont joué de leur mestier devant le Roy [...], le 19 sept. à Compiègne, 80 s.p. ${ }^{75}$ Diese Indifferenz zwischen Herolden und Spielleuten hat sich zumindest im deutschen Raum auch noch über das 15. Jahrhundert hinweg erhalten (obgleich auch hier an verschiedenen Fürstenhöfen Herolde und Wappenkönige in gleichen oder ähnlichen Funktionen wie in Frankreich bekannt sind $^{76}$ ). So wurde in den Aachener Stadtrechnungen noch für das Jahr 1467/68 ein

68 Vgl. van AnRool, Spiegel van ridderschap, S. 48 m. Anm. 266.

69 Vgl. van den Neste, Tournois, Nr. 211.

70 Vgl. UytTeBrouck, Gouvernement, Bd. I, S. 222.

71 Auf die Herkunft dieser Bezeichnung verwiesen bereits WAGNER, Heralds of England, S. 5 und Uyttenbrouck, Gouvernement, I, S. 223, der hier für die zeitweilige Konfusion der Bezeichnungen aus einem Geleitbrief des Johann IV. von Brabant von 1420 zitiert, dessen Empfänger als armorum sive heraldorum Brabantie rex qualifiziert wird (ibid., S. 223, Anm. 495).

72 Vgl. den oben erwähnten Textausschnitt aus dem »Restor du Paon« (Anm. 65).

$73 \mathrm{Zu}$ den >anderen< Könige in Spätmittelalter und Frühneuzeit vgl. mit Beiträgen zu den rois des ménestrels, rois des ribauds, rois des compagnons und anderen HiLTMANN (Hg.), Les $>$ autres< rois.

$74 \mathrm{Zu}$ den Wappenkönigen selbst vgl. insbesondere STEVEnson, The Scottish King of Arms, und SIMONNEAU, Le roi d'armes.

75 DouËT D’ARCQ (Hg.), Comptes de l'Hotel, S. 185. Für den deutschen Raum vgl. z. B. die Aufzählung der Anwesenden zum Fürsten- und Städtetag in Frankfurt am Main im Mai 1397: Item 600 geralde und varende lude (HöHLBAum, Der Fürsten- und Städtetag, S. 82). 76 Vgl. z. B. den Geleitbrief des Meißener Markgrafen Friedrich IV., des Streitbaren, für sei- 
Betrag von $18 \mathrm{~s}$. für eyn dwerch, was eyn heralt, sprach spruchen $v p$ dat huy $\beta$ vnsen herren verbucht ${ }^{77}$. Selbst am Ende des 15. Jahrhunderts wurden in Deutschland Herolde immer wieder als Sprecher und Sprecher immer wieder als Herolde bezeichnet ${ }^{78}$. Als beredtes Zeugnis, welches zugleich auf die soziale Stellung der so Bezeichneten verweist, sei hier das 1494 entstandene »Narrenschiff« des Sebastian Brant zitiert. Hier heißt es im Kapitel zu den Bettlern:

Eyn wild begangenschafft der welt

Ist wie man stelt yetz uff das gelt

55 Herolden/sprecher / Partzifand/

Die strofften ettwann öfflich schand

Und hatten dar durch eren vil

Eyn yeder narr yetz sprechen wil

Und tragen stäblin ruch und glatt

60 Das er werd von dem bättel satt ${ }^{79}$.

In Frankreich und im burgundischen Raum waren die Verhältnisse andere. Doch blieben auch hier mindestens bis in die Anfänge des 15. Jahrhunderts noch enge personale Kontinuitäten erhalten, rekrutierte sich ein Teil der Herolde, selbst der fürstlichen Herolde, aus dem Milieu der Fahrenden. So ist in den Brabanter Rechnungen für 1414/15 ein gewisser Coenrad noch als fifre et trompette erwähnt, der zehn Jahre später ebendort als Wappenmarschall von Brabant genannt wird ${ }^{80}$. Und selbst ein so berühmter Wappenkönig wie Nicolas Villart, genannt Calabre, der an herausragender Stelle an der Gründung der Heroldsvereinigung von SaintAntoine-le-Petit (1407) beteiligt war und der zu den Unterzeichnern der »Ersten Supplik« an den französischen König gehörte, wurde noch acht Jahre vor seiner Krönung zum Wappenkönig von Anjou und Touraine (1389) in den königlichen Rechnungen als ménestrel de bouche erwähnt ${ }^{81}$.

Selbst wenn sich die personalen Bindungen zwischen Spielleuten und (zumindest) fürstlichen Herolden im 15. Jahrhundert gelöst haben sollten, institutionell

nen Herold Johann Missenland, mit Angaben über dessen Aufgaben Codex diplomaticus Saxoniae regiae, Reihe B, Bd. I, IV, S. 95.

77 Vgl. PietzsCH, Musik in Reichsstadt, S. 98.

78 Jacob Strawbinger, der unter anderem 1458 im Augsburger Baumeisterbuch als partzifant hertzog Albrechtz von München (Albrecht III.) und 1477 in den Regensburger Rechnungen als Herold Herzogs Albrecht IV. bezeichnet wird, ist nach Gerhard Pietzsch auch des öfteren als Sprecher genannt - laut Pietzsch kein Einzelfall, vgl. DeRS., Fürsten und fürstliche Musiker, S. 153, Anm. 106.

79 Sebastian Brant, Das Narrenschiff, S. 155 (Kap. 63, Z. 53-60).

80 Vgl. UytTeBrouck, Gouvernement, I, S. 223.

81 So geschehen in den Rechnungen des Hofes Karls VI. aus dem Jahre 1381, DouËT D'ARCQ, Comptes de l'Hotel, S. 185 f. Und auch am Hof von Navarra rekrutierten sich die Herolde zuerst aus dem Milieu der Spielleute und trugen wie Pierre de Bar auch als Herolde noch eine Harfe in ihrem Wappen, vgl. NARBONA, L'origine de l'office d'armes. Im übrigen war eine Karriere auch auf umgekehrtem Wege möglich. So läßt sich im Marienburger Tresslerbuch die Karriere eines Nuneke nachverfolgen, der vor 1404 immer wieder einmal als Sprecher oder auch als Herold genannt wird, nach diesem Zeitpunkt aber regelmäßig als Narr erscheint, dem auch ein Narrengewand bezahlt wird, vgl. BoocKMANN, Spielleute und Gaukler, S. 223 m. Anm. 40-43. 
blieben sie noch länger bestehen ${ }^{82}$. So erscheinen die Herolde in den burgundischen Hofordnungen - auch wenn sie, wie es bei Olivier de La Marche heißt, nur dem Herzog und dem ersten Kammerherrn unterstellt waren ${ }^{83}$ - stets im direkten Umfeld der Spielleute und Trompeter ${ }^{84}$. Nur die Persevanten wurden einige Zeit aus dieser Gruppe ausgegliedert und unter den Boten und Reitern der escurie eingeordnet, wie dies in den Hofordnungen von 1438 und 1445 der Fall war ${ }^{85}$.

Um das Bild der sozialen Herkunft der Herolde zu komplettieren, sei darauf verwiesen, daß auch die escurie mit ihren Reitern und Boten ein wichtiges Rekrutierungsfeld für das office d'armes darstellte, das sich aus der beiden gemeinen Reise- und Botentätigkeit ergab. So berühmte Herolde wie Gelre und Berry entstammten diesem Umfeld, obgleich beide vorrangig für ihre schriftlichen Hinterlassenschaften bekannt sind ${ }^{86}$.

Die Gagen der Herolde und Persevanten waren zumindest in den burgundischen Hofordnungen stets kleiner bemessen als die der verschiedenen Spielleute und Trompeter. Nur die Wappenkönige bezogen wie diese eine Tagesgage von 12 s. bzw. verfügten über einen Diener und zwei Pferde. Herolde und Persevanten lagen mit 9 s. bzw. 6 s. darunter ${ }^{87}$.

Die besagte institutionelle Bindung zwischen Herolden und Spielleuten wird aber am deutlichsten, wenn es um die Verteilung von Geschenken geht. Hier werden beide Gruppen stets gemeinsam genannt. So berichtet Georges Chastellain, daß Philipp der Gute von Burgund 1463 den englischen Botschaftern und ihren Begleitern zahlreiche Geschenke machte, mesmes jusques aux ménestriers, héraux et gens de bas instrumens ${ }^{88}$. Gleiches läßt sich immer wieder bei den largesses zu den vier bzw. fünf höchsten Feiertagen des Jahres beobachten. Hier ist es während des gesamten 15. Jahrhunderts in Burgund ${ }^{89}$ nicht anders als am französischen Königshof oder am Hof der Herzöge der Bretagne ${ }^{90}$, obgleich die Herolde

82 Dies hat bisher einzig für den deutschen Raum beobachtet: HEINIG, Türhüter und Herolde, S. 355-375.

83 Vgl. den »Estat de la maison du duc Charles de Bourgoigne, dit le Hardy« von Olivier de La Marche, in: Olivier de La Marche, Mémoires, Bd. IV, S. 1-94, hier S. 67-70.

${ }^{84}$ Für die Hofordnungen Philipps des Guten vgl. Hofordnungen, Bd. I, für jene aus der Regierungszeit Karls des Kühnen vgl. Hofordnungen, Bd. II.

$85 \mathrm{Vgl}$. Hofordnungen, Bd. I, für die Hofordnung Philipps des Guten von 1438, Nr. 11, $\S 301,304-306$ und für dessen Hofordnungsprojekt von 1445, Nr. 15, § 261-264.

86 So war z. B. Claes Heynenzoon, der berühmte Herold Gelre, der für mehrere Chroniken, Wappenbücher und Ehrenreden verantwortlich war, vor seiner Heroldslaufbahn am Hof der Herzöge von Geldern Bote des Johann von Châtillon-Blois, vgl. van ANROOIJ, Spiegel van ridderschap, S. 56-66. Gilles Le Bouvier, der v. a. für seine Chronik bekannte Herold Berry, wird in Rechnungen des Dauphin im November 1420 noch als Gilles Le Bouvier, chevaucheur de l'escuierie de Monseigneur genannt, vgl. VALLET DE VIRIVILLE, Notice sur la vie, S. 214 m. Anm. 1; weitere Beispiele für die Bretagne bei JoNES, Vers une prosopographie des hérauts, S. 1409.

87 Die hier in den Hofordnungen zum Ausdruck kommende Hierarchie muß jedoch nicht notwendig auch die bei Hofe sein, vgl. PARAVICINI, Europäische Hofordnungen, S. 18.

88 Georges Chastellain, Euvres, Bd. IV, S. 390.

89 Vgl. Heraudica, sources, z. B. nos 17486 (1368), 12890 (1418), 12860 (1466).

$90 \mathrm{Vgl}$. Jones, Vers une prosopographie des hérauts, S. 1412. 
hier - wie eben erwähnt - wohl einen besseren Stand genossen. Wie in den früheren Zeiten auf den Turnieren erhielten sie die largesse ihrer mittlerweile festen Dienstherren noch immer gemeinsam mit den Spielleuten und Trompetern, mit denen diese zu teilen war. Dies galt 1480 noch in der gleichen Weise wie einhundert Jahre zuvor ${ }^{91}$.

\subsubsection{Ehre und Kommunikation von Ehre als zentrale Elemente des Heroldswesens}

Damit wieder bei den Ursprüngen des Heroldswesens angelangt, gilt es von hier aus nun einer anderen Fährte zu folgen, die das bisher so heterogene Bild der Herolde zwischen ihren verschiedenen Aufgaben, ihrem weitgefaßten sozialen Spektrum und ihrer fortdauernden Verbindung zu den Spielleuten zu einen vermag. Diese folgt dabei einer sozialen Funktion, die die Herolde schon von Beginn an innehatten und in der, wie Werner Paravicini bereits resümierte, nichts weniger als die »Essenz« ihrer Tätigkeit lag92. Während die ältere Forschung diese meist nur als Randerscheinung wahrnahm ${ }^{93}$, konnte Gert Melville zeigen, daß sie vielmehr die eigentliche gesellschaftliche Bedeutung der Herolde repräsentiert und den Schlüssel zum Verständnis dieses Amtes und seines Aufstiegs in der spätmittelalterlichen Adelskultur in sich birgt ${ }^{94}$ : die Zuweisung und Kommunikation von Ansehen und Ehre95.

91 Für 1480/81 vgl. einen Rechnungseintrag unter Ludwig XI. zum Neujahrstag, wo es unter der Rubrik: Dons et Recompensacions heißt: A Normandie, roy d'armes, Montsenys et Touraine, héraulx, Jehan Conyn, Pierre de Molins, Clemens Tourtolon et Berthelemy des Marests, trompectes, la somme de cent livres tournois, que ledict seigneur [le roi] lui a donnée pour leurs estrainnes du premier jour de l'an mil cccc iiij ${ }^{x x}$. (DOUËT D'ARCQ, Comptes de l'Hotel, S. 395). Vgl. dazu einen Rechnungseintrag in den Rechnungen Karls VI. aus dem Jahre 1380: Les héraux et ménestriers qui ont esté devers le Roy le dymanche iie jour de juing, le jour de Penthecouste, pour don fait à eulx par cédulle dudit seigneur, ce jour, illec, 80 l.p. (ibid., S. 115).

92 Vgl. PARAVICINI, Ritterlich-höfische Kultur, S. 80: »Der Herold aber wird zum Spezialisten, zum Makler, tendenziell zum Monopolisten der Ehrzuteilung. Dies ist die Essenz seiner Tätigkeit in Turnier und Krieg, Rechtshandlung und diplomatischem Verkehr, Spruch und Chronik: Zuteilung, Kommunikation und Registratur von Lob und Tadel«. Zur Rolle der Herolde in der öffentlichen Ehrzuweisung vgl. v. a. KEEN, Chivalry, S. 125-142, der jedoch vorrangig englische Beispiele heranzieht.

93 Vgl. v. a. WAGNER, Heralds and Heraldry, S. 25-45 und DERS., Heralds of England, S. 1-123 passim.

94 Vgl. Melville, Hérauts et héros, v. a. S. 93-96 und Ders., »Un bel office«, insbes. S. 292 f., 320 f. Siehe ausführlicher noch unten, Kap. 5.2.

95 Der Begriff der »Ehre« ist in diesem Zusammenhang einerseits als persönliche Ehre zu verstehen, so wie sie Norbert Elias definierte, als »Ausdruck der Zugehörigkeit zu einer Adelsgesellschaft. Man hatte seine Ehre, solange man nach der >Meinung < der betreffenden Gesellschaft und damit auch für das eigene Bewußtsein als Zugehöriger galt. Die Ehre verlieren, hieß die Zugehörigkeit zu seiner >guten Gesellschaft « verlieren « (ELIAS, Die höfische Gesellschaft, S. 154f.). Er sollte zugleich aber immer auch im Sinne der Standesehre verstanden werden, womit er eben nicht allein die Zugehörigkeit und Stellung des einzelnen Adligen zur Adelsgesellschaft beschreibt, sondern auch den Abschluß des Standes als gan- 
Die Auseinandersetzung mit den einzelnen Edelleuten und deren Renommee stand von Anfang an im Mittelpunkt der Beschäftigung der Herolde. Alle weiteren Aufgaben, welche sie später einmal übernehmen sollten, können dieser untergeordnet werden oder sind aus dieser zu erklären. Vor allem die Heraldik, welche gern auch als Selbstzweck des Heroldsamtes beschrieben wird, diente vorrangig diesem Ziel. Denn nicht die Kenntnis der Wappen, sondern die Kenntnis der Person stand für das Heroldsamt im Vordergrund. So war es bereits bei den ersten Herolden, wenn sie neben dem Namen der jeweiligen Kämpfer auch deren Leumund zum besten gaben und vertraten. Bei dem bereits erwähnten Geleitbrief Karls VI. für seinen Persevanten Jamais ist es nicht anders, wenn es heißt, dieser habe

entencion d'aler d'illec en pluseurs autres pays et contrees pour acquerir honneur et avoir plus grant cognoissance des seigneurs et dames desdiz pays et de leurs armes ${ }^{96}$.

Die dem Wappen zugemessene Bedeutung erklärt sich vielmehr daraus, daß dieses neben seiner klaren Funktion als Erkennungszeichen zugleich auch als herausragendes Symbol seines Trägers und damit als wesentlicher Bestandteil der zu ehrenden Person begriffen wurde. Das Wappen repräsentierte Person und Familie wie den Adel als Ganzes und wurde als solches von den Herolden auch zu den verschiedensten Gelegenheiten in Szene gesetzt. Die Beschäftigung mit den Wappen war somit kein Selbstzweck der Herolde. Ziel war vielmehr die Kennzeichnung und Erkennung, wie auch die Repräsentation und Ehrung der jeweiligen Besitzer. In diesem doppelten Sinne ist dann auch die Anlage und Sammlung von Wappenbüchern wie die Schaffung einer eigenen, speziellen Sprache zur korrekten Beschreibung der Wappen zu verstehen, der Blasonierung. Und da mit dem Wappen immer auch die damit bezeichnete Person verbunden war, konnte das Wort »blasonner « - in seiner Bedeutung meist nur auf die Beschreibung der Wappen verengt - auch im Sinne von »loben« oder »schmeicheln« verwendet werden ${ }^{97}$. Die Kenntnis der Wappen war für die Herolde somit nicht das Ziel, sondern die Voraussetzung für die Erfüllung der verschiedenen Aufgaben ihres Amtes, sei es im Turnier- und Kriegswesen, in der höfischen Repräsentation oder in der Beobachtung und Verbreitung von Ansehen und Ehre.

Am Beginn der Geschichte ihres Amtes erlangten die Herolde ihr umfangreiches Wissen von Ritterschaft, Adel und Wappen während ihrer ständigen Reisen von Turnier zu Turnier. Später unternahmen sie eigens Reisen, um dieses Wissen zu erlangen. Ihre Kenntnis fremder Länder und fremden Adels prädestinierte sie dabei geradezu zum Botendienst, der seinerseits, wie ihre Aufgaben im Kriegs-

zen gegenüber anderen gesellschaftlichen Gruppen befördert. Zum Begriff der Standesehre vgl. SiMMEL, Soziologie, S. $404 \mathrm{f}$.

96 Viellard, Avezou (Hg.), Lettres originales, S. 359.

97 Vgl. Greimas, Keane, Dictionnaire, S. 67, s. v. »blasonner«. Für einige Textbeispiele vgl. La CuRne de SaInTe-Palaye, Dictionnaire historique, s. v. »blasonner «. Dieser zitiert u. a. folgende Stelle aus der »Histoire du Chevalier Bayard«: Tellement le louoit et blasonnoit, que le pauvre gentilhomme en rougissoit de honte. 
wesen, ihre Erfahrungen nur noch erweitern konnte. Auch hier wurde nicht nur gedient, sondern auch beobachtet, gesehen, erfahren.

Das so angehäufte Wissen machte sie unter anderem zu Ratgebern in den Fragen des droit d'armes ${ }^{98}$ wie insgesamt der Spielregeln der ritterlich-adeligen Welt. Als solche erscheinen sie häufiger in der Literatur, wie zum Beispiel im »Tirant lo Blanc« von Joanot Martorell aus der Mitte des 15. Jahrhunderts. Als der junge Held von einem ihm mißgünstigen Gegner eine Herausforderung zum Duell erhält, erkundigt er sich sogleich bei einem Wappenkönig nach der angemessenen Reaktion und läßt sich von diesem beraten ${ }^{99}$. Doch auch die Historiographie bietet vereinzelte Belege. So schildert Olivier de La Marche, wie der im Dienste des Herzogs von Mailand stehende Galiot de Baltasin vor der Zustimmung zu einem Zweikampf mit Philipp de Ternant sich zuerst bei den Wappenkönigen und Herolden nach den entsprechenden Gewohnheiten in Burgund erkun$\operatorname{digt}^{100}$. Als Gewährsleute in derlei Fragen erscheinen die Herolde in gleicher Weise in der Traktatliteratur, wenn Antoine de La Sale seinen Turniertraktat mit einer Erläuterung der Gründung der Turniermarken unter Karl dem Großen beginnt und diese mit den Worten einleitet:

Monseigneur, j'ay trouvé par anciens livres, par relacions et rappors de autenticques roys d'armes et heraulx $[\ldots]^{101}$.

Doch mehr noch als von den Regeln der ritterlichen Welt wußten die Herolde von deren Ereignissen und Protagonisten zu berichten. Als deren Kenner wurden sie bereits von Jacques Bretel in seinem Bericht über das Turnier von Chauvency (1285) erwähnt, wo sie wißbegierigen Damen wie dem Verfasser selbst neugierige Fragen zu den einzelnen Rittern, deren Taten und deren Familien beantworteten ${ }^{102}$. Spätestens mit ihrem Eintritt in den fürstlichen Dienst ist immer wieder auch von einem Amtseid die Rede, der sie dazu anhält, ohne Gunst und Ansehen der Person stets und immerfort die Wahrheit zu berichten und nicht nur ihrem

$98 \mathrm{Zu}$ dem für die spätmittelalterliche Adelskultur wichtigen Begriff des droit d'armes und seiner Bedeutung (für dieselbe) gibt es meines Wissens noch keine eingehende Untersuchung. Er bezeichnet das für die Ritterschaft geltende Standes- und Kriegsrecht, umfaßt dabei aber auch das Wappenrecht oder die Regeln auf Turnieren. Er ist Verhaltenscodex, Gewohnheitsrecht und Zeremoniell zugleich. Zumindest für eine kurze Einleitung zum droit d'armes vgl. JÄGER, Aspekte des Krieges, S. 59-66, sowie ConTAMINE, Guerre, État et société, S. 187-192, 202 f.

99 Joanot Martorell, Tirant lo Blanc, Capítol LXIII: »Com Tirant demanà de consell a un rey d'armes sobre la letra del senyor de les Viles-Ermes«.

100 Lors demanda Galiot aux roy d'armes et heraulx la coustume du pays: et dit qu'en son pays, quant le requerant arrache l'emprinse de son compaignon, c'est pour la vie de l'ung ou de l'autre, mais quant l'on n'y fait que toucher seulement, c'est pour chevalerie. Sur quoy luy respondit Thoison d'or que le seigneur de Ternant avoit chargé son emprinse pour chevalerie et que la coustume estoit de toucher à l'emprinse quant on est present (Olivier de La Marche, Mémoires, Bd. II, S. 66).

101 Antoine de La Sale, Le traité, S. 300.

102 Vgl. Jacques Bretel, Le Tournoi de Chauvency, v. 283-389 und 1017-47. 
eigenen Herrn, sondern dem gesamten Adel loyal zu dienen ${ }^{103}$. Dies machte sie zu willkommenen Gewährsleuten von Chronisten wie Froissart, Enguerran de Monstrelet, Jean de Wavrin oder Molinet ${ }^{104}$. Sich selbst bezeichneten die Herolde gern auch als voir disants, als jene, die die Wahrheit sagen.

Mitunter schienen sie die großen Ereignisse im Leben eines Ritters sogar mit Brief und Siegel bestätigt zu haben. So ist aus dem Jahre 1456 ein Schreiben des Herolds Kastilien überliefert, mit dem dieser die Ritterweihe des Jean de Rebreviettes beglaubigt. Dabei schildert er den heldenhaften Einsatz des Ritters bei der Erstürmung der Stadt Jimena und dessen Zweikampf mit einem Sarazenen, den er dabei bezwang. Daraufhin habe der König von Kastilien selbst den tapferen Ritter zu sich gerufen, um ihn - gegen seinen bescheidenen Protest - mit dessen eigenem, noch blutigem Schwerte zum Ritter zu schlagen ${ }^{105}$.

Ihre höchste Ausformung fand die genannte Funktion in den Statuten der weltlichen Ritterorden des 15. Jahrhunderts, wo sie den Herolden eigens als feste Aufgabe formuliert wurde ${ }^{106}$. Entsprechend heißt es in den Statuten des Ordens vom Goldenen Vlies, deren entsprechende Passagen später für den Michaelsorden des französischen Königs oder mit der Reform von 1518 auch für den Ordre d'Annonciade des Herzogs von Savoyen übernommen wurden:

Item, que ledit herault Thoison d'or enquerra diligenment des proesses et haulx faiz et honnorables du souverain et des chevalliers de l'ordre, dont il fera veritable rapport au greffier de l'ordre pour estre mis en escript comme faire se devra107.

Die Rolle der Herolde beschränkte sich dabei aber nicht nur auf die des unvoreingenommenen Beobachters und Berichterstatters adeliger Ereignisse und ritterli-

103 Zur besonderen Bedeutung des Amtsschwures und der daraus abzuleitenden Konsequenzen für die Charakterisierung der Herolde als personnes publiques im Dienste von Diplomatie und adeliger Ehre vgl. grundlegend HiLTMANN, Vieux chevaliers.

104 Vgl. v. a. STANESCO, Le héraut d'armes, v. a. S. 247-249. So heißt es z. B. bei Froissart am Beginn der dritten Redaktion seiner Chronik: Afin que les grans merveilles et li biau fait d'armes qui sont avenu par les grans guerres de France et d'Engleterre et des royaumes voisins, dont li roy et leurs consaulz sont cause, soient notablement registré et ou temps présent et à venir veu et cogneu, je me voel ensonnier de l'ordonner et mettre en prose selonch le vraie information que j'ay eu des vaillans hommes, chevaliers et escuiers, qui les ont aidiet à accroistre, et ossi de aucuns rois d'armes et leurs mareschaus qui par droit sont et doient estre juste inquisiteur et raporteur de tels besongnes (Froissart, Chroniques, Bd. II, S. 7).

105 Ein Auszug aus der Urkunde findet sich in englischer Übersetzung bei KeEN, Chivalry, S. 167 nach Besançon, Bm, Coll. Chifflet 83, fol. 58. Zur näheren Einordnung und weiteren Textzeugnissen vgl. PARAVICINI, Georg von Ehingens Reise, S. 560, Anm. 63. Ein weiterer, weitaus späterer Bestätigungsbrief durch Loys de Beaunoys, roy d'armes ordinaire du roy für einen gewissen Etienne Barbault, der im Dienste des Seneschall der Normandie stand, ist aus dem Jahre 1519 überliefert (vgl. Paris, BnF, fr. 5242, fol. 91r).

106 Zur Funktion der Herolde in Ritterorden vgl. MelviLle, Rituelle Ostentation, S. 235, S. 240-248 und Ders., Hérauts et héros, S. 87, S. 92.

107 DÜNNEBEIL (Hg.), Protokollbücher, Bd. I, S. 212. Als weitere Ordensherolde sind neben den Wappenkönigen Saint-Michel (Michaelsorden) und Bonnes Nouvelles (Ordre d'Annonciade) auch Loz (Halbmondorden Renés d'Anjou) und - als Urtyp aller - der Wappenkönig Garter (Hosenbandorden) zu nennen. Zu den Herolden der weltlichen Ritterorden und dem Vorbildcharakter Garters bzw. des Toison d'or vgl. HiLtmann, Tournois et héraudie. 
cher Taten. Schon von Anbeginn an waren sie auch Teil deren Inszenierung. Die Grundlagen ihrer späteren repräsentativen Aufgaben wurden auf den ersten Turnieren gelegt, an denen sie teilnahmen ${ }^{108}$. Bereits hier begleiteten sie die einzelnen Kämpfer auf das Turnierfeld ${ }^{109}$ und riefen deren Kampfrufe und deren Namen:

Hiraut crioient noblement:

Couchi, Couchi au vaillant homme

De cui de France jusqu'a Romme

Doit li renons de lui aler!

Couchi au vaillant baceler,

Couchi au castellain, Couchi!110

Auch an den Ehrentisch auf der Marienburg während der Preußenreisen im 14. Jahrhundert sei hier erinnert, wo es den Herolden oblag, die besten und tapfersten Kämpfer zu wählen, die an diesem Platz nehmen durften ${ }^{111}$.

Nicht nur bei Zeremonien zur Ehrvermehrung, sondern auch bei Entehrungen traten die Herolde in Erscheinung, auch wenn hierfür weit weniger Belege bekannt sind. Sicherlich einem politischen Zweck zuzuordnen ist ein Ereignis, welches im Jahre 1395 dem Wilhelm von Ostrevant, Sohn des holländischen Grafen Albrecht von Bayern während seines Aufenthaltes in Frankreich widerfuhr. Zum Fest der Heiligen Drei Könige in gemeinsamer Runde mit mehreren Fürsten zerschnitt ein Herold vor ihm das Tischtuch und sprach ihm das Recht ab, ein Schild tragen zu dürfen. Schließlich habe er den Mord der Friesen an dem Bruder seiner Großmutter, dem ehemaligen Grafen Wilhelm IV. von Holland, nicht gerächt (der zu diesem Zeitpunkt bereits fast fünfzig Jahre zurücklag). In Begleitung von neunzehn Herolden zog Wilhelm von Ostrevant ein Jahr später gegen die Frie$\operatorname{sen}^{112}$. Um eine handfeste Entehrungszeremonie handelte es sich hingegen im

108 Vgl. hierzu auch Melville, Hérauts et héros, S. 82.

109 So heißt es bereits in Jean Renarts »Roman de la Rose ou de Guillaume de Dole« vom Anfang des 13. Jahrhunderts: O tot .LX. conpegnons / toz armez, les heaumes laciez, / les penons au vent desploiez, / s'en vet vers le tornoiement, / et hyraut aprés lui tex. C., / quil font a mervelle esgarder. / Et tuit dient: „Car lai aler, / c'est Guillames de Dole, queles! «(Jean Renart, Roman de la Rose, Z. 2632-2639).

110 Jakemes, Roman du Castelain, Z. 1301-06. Andere Beispiele finden sich bei BumKE, Höfische Kultur, S. 369-371.

111 Vgl. Paravicini, Preußenreisen, Bd. I, S. 316-329 mit einem Auszug aus den 155 Articuli contra Cruciferos des Paulus Vladimiri, die dieser zum Zwecke der Häresieanklage gegen den Deutschen Orden vor dem Konstanzer Konzil 1416 fertiggestellt, aber nicht veröffentlicht hat: Cuius quidem »mensae honoris « taliter appellatae, licet per dictorum fratrum vanitatem adinventae, mos erat et est talis, qoud prandio aliquot personis et hospitibus huiusmodi, puta pro decem vel pro duodecim, vel in alio pauco numero, per eosdem Fratres solemniter praeparato, dumtaxat illae personae ex millibus electae per araldos ibidem praesentes ad praedictam mensam locabantur. Quae personae, testimonio eorundem araldorum plures mundi partes causa militiae peragrarunt et in pluribus regnis et aliis partibus visae sunt per araldos (zitiert nach ibid., S. 321).

112 Anno Domini 1395 in festo Epiphanie Domini cum illustrissimus Dux Wilhelmus Comes Oesteruant sederet ad mensam Francorum Regis cum multis aliis Principibus, ecce superuenit quidam Heraldus seindens \& diuidens mensale ante iam dictum Comitem Wilhelmum as- 
Falle des burgundischen Landvogtes im Breisgau, Peter von Hagenbach, als er vor seiner Hinrichtung durch einen Herold all seiner Ritterschaft entkleidet wurde $^{113}$. Und auch der Wappenkönig Toison d'or entehrte einmal öffentlich, während der Messe anläßlich eines Ordenskapitels, das Wappen eines illoyalen Mitgliedes, wobei er hörbar laut und für alle verständlich die Anschuldigungen verlas, die gegen diesen vorgebracht wurden ${ }^{114}$.

Die Herolde gerieten somit selbst zum Mittelpunkt von Inszenierungen, in deren Zentrum Ehre und ritterliches Verhalten standen. Dabei wurden sie nicht nur als die Vertreter ihres Dienstherren, sondern auch als die Personifikation der ritterlichen Ehre an sich in Szene gesetzt, was nur mit einer besonderen Würde, einer besonderen Geltung zu erklären ist, die man ihnen in derlei Fragen zusprach. Deutlichster Beleg hierfür ist der deutsche Begriff »ernhold «, welcher im Verlaufe des 15. Jahrhunderts aus dem französischen Lehnwort »herolt« abgeleitet wurde und der nichts anderes heißt als »Diener der Ehre «115.

Diese Geltung aber, welche letztlich zu den genannten Inszenierungen der Herolde führte, beruhte nicht nur auf ihrer Funktion als omnipräsente Registratoren und gelegentliche Gewährsleute ritterlicher Taten. Die Herolde waren deren eigentliche Publizisten. Sie wirkten in ihrer Zeit geradezu als die professionellen Kommunikatoren von Tat und Ereignis, von Ansehen, Ehre und ritterlichen Werten. Mit dem Weitertragen und Verbreiten von Informationen und Wertungen ist aber vielmehr eine stete Funktion, eine Grundeigenheit des Amtes beschrieben, denn eine klar definierte Aufgabe, die sich ohne weiteres in Rechnungsbüchern

serens non decere Principem sedere aliquem ad mensam Regis, qui clypeo seu armis priuatus esset, \& cum idem wilhemus repondisset si habere clypeum \& arma, rursus Heraldorum senior ait, Nequa quam Domine mu, quia Wilhelmus quondam Comes Hollandia Auus quondam proauundulus nedum interfectus est a Frisonibus, sed \& hodierna die adhuc inuindicatus iacet in terra inimicorum suorum. (Johannes Gerbrand von Leiden, Chronicon Hollandiæ, Bd. I, S. 312). Zu dem darauffolgenden Kriegszug vgl. VeRwIJs, De oorlogen. Ein literarischer Beleg für das Zerschneiden des Tischtuches durch einen Herold findet sich in »Des Teufels Netz« von ca. 1414-1418, wo es an einer Stelle v. a. um Adel und Turnier, um Neid, Hass und ritterliches Verhalten geht. Hier heißt es: Es wurden och die lastberer bescholten / Von den barzafar und herolten; / Wo si kamen für si ze tisch, / Da schnitten si das tischlach frisch / Den herren von der schosse, / Das si sassen rott und blosse / Und grosz scham enphiengen / Und in übel im turner ergiengen. (BARACK [Hg.], Des Teufels Netz, v. 7786-7793).

113 Vgl. das Lied eines Hans Judensint zu Peter von Hagenbach und dem angesprochenen Ereignis in LiLIENCRON (Hg.), Historische Volkslieder, Bd. II, Nr. 132, S. 33-37, sowie eine anonyme »Reimchronik zu Hagenbach«, in: MonE (Hg.), Quellensammlung, Bd. III, S. 183-256, hier S. 385. Eine ähnliche Aufgabe übernahmen englische Herolde vor der Hinrichtung des aufständischen Sir Ralph Grey, dem sie öffentlich den Wappenrock auszogen, vgl. LESTER, Fifteenth-Century English Heraldic Narrative, S. 202.

114 Vgl. Georges Chastellain, Euvres, Bd. V, S. 377. Vgl. dazu auch DünNEBeIl (Hg.) Protokollbücher, Bd. II, S. 84.

115 Ernhold, in: GRIMM, Deutsches Wörterbuch, Sp. 218 f. Die gleiche Entwicklung läßt sich auch im niederländischen Sprachraum nachverfolgen, vgl. Eeronthout, in: VERDAM u.a. (Hg.), Middelnederlandsch Woordenboek, Bd. II, Sp. 566. 
abrechnen ließe ${ }^{116}$. In dieser Funktion, welche die kleinen Persevanten und die etablierten Wappenkönige in gleicher Weise verband, fanden sie ihren festen Platz in der spätmittelalterlichen Gesellschaft. Zur Ausübung dieser Funktion bedurften sie aber immer noch der kommunikativen Fähigkeiten der Spielleute respektive der Sprecher, denn all dies geschah zum überwiegenden Teil mündlich ${ }^{117}$.

Eine der Folgen ist, daß die überkommenen Quellen nur ein verzerrtes Bild der tatsächlichen Situation wiedergeben können, da dieses Wirken der Herolde nur aus zweiter Hand zu rekonstruieren ist. Sie können damit nur eine grobe Vorstellung davon liefern, in welcher Weise und in welchem Umfang die Herolde tatsächlich Einfluß auf die öffentliche Wahrnehmung nahmen.

$\mathrm{Ob}$ in ihren Anfängen oder am Ende des Mittelalters, die Herolde standen stets in dem Ruf, lautstark die Ehre und das Ansehen der einzelnen, insbesondere ihrer Herren, zu mehren und zu verbreiten. Im »Perceforest « zum Beispiel wurden die Begriffe heraux und nonceurs de proesses gleichwertig für jene gebraucht, welche die Heldentaten der Ritter verkündeten ${ }^{118}$. Und in Chaucers »House of Fame«, das 1380 entstand, ist zu lesen: That pursevantes and heraudes, / That crien ryche folkes laudes ${ }^{119}$.

Und auch Eustache Deschamps meint das gleiche, wenn er klagt: Je n'ai mais bon seneschaut, / Ne pour moi louer herault 120 .

Wie die Verbreitung von Information und von Ansehen durch die Herolde möglicherweise vonstatten ging, soll im folgenden kurz an einigen Quellenbelegen demonstriert werden.

$116 \mathrm{Zu}$ den wenigen Spuren in den Rechnungsquellen vgl. die Abrechnung für einen Meißner Herold, der 1434 am Gelderschen Hof dafür bezahlt wurde, daß er neue mere brachte von dem kyser (Arnheimer Stadtrechnungen, zitiert nach: NIJSTEN, Het hof van Gelre, S. 327, Anm. 15).

117 Darauf verwiesen hat bereits MelviLle, Hérauts et héros, S. 91. Eines der wenigen Zeugnisse, welche sich von dieser Tätigkeit der Herolde noch finden lassen, konnte Bertrand SCHNERB, Musique, S. 16-21, präsentieren. Ihm gelang es, den Autor des kurzen Gedichtes »La bataille du Liège«, der sich selbst nur Ruelle nennt, möglicherweise mit Jacquet de La Ruelle zu identifizieren, der zwei Jahre nach dem Ereignis, 1410 also, als Persevant Talent im Dienste des burgundischen Herzogs Johanns Ohnefurcht erwähnt wird (zur Person vgl. Heraudica, personnes, $\mathrm{n}^{\circ}$ 0051). Das Gedicht selbst, der Form nach an eine Reimchronik erinnernd, berichtet in knappen Worten von den Ereignissen bei der Schlacht von Othée (23. September 1408), als es Johann III. von Bayern allein mit der Hilfe seiner Verbündeten gelang, den Aufstand der Lütticher niederzuschlagen. Im Text selbst aber erfahren insbesondere die Verdienste des burgundischen Herzogs Erwähnung. Zugleich ist es das erklärte Ziel des Stückes, den Adel zu preisen und von dessen Tapferkeiten zu berichten, wobei zahlreiche der anwesenden Ritter und Knappen auch namentlich genannt werden. Besonders hervorgehoben werden dabei jene, die an diesem Tage ihren Ritterschlag erhalten haben - womit der Text eigentlich alles erfüllt, was von einem Herold/Persevanten in diesem Falle zu erwarten war.

118 Vgl. Roussineau, Perceforest, Bd. II, Genf 2001, S. 321, Kap. 597, Z. 13.

119 Geoffrey Chaucer, House of Fame, in: Benson (Hg.), The Riverside Chaucer, S. 347373, hier S. 364, v. $1321 \mathrm{f}$.

120 Zitiert nach La CURnE DE SAINTE-PALAYE, Dictionnaire historique, s. v. »heraut«. 
So berichtet beispielsweise der Chronist Froissart, wie die Herren Jehan d'Auberchicourt und Martin Ferrant de Merlo auf ihrem Weg durch Galizien dem portugiesischen Herold Coimbra begegneten:

Le hérault avoit jà parlé aux seigneurs et dit les nouvelles, quant Ferrant Martin de Merlo qui chevauchoit tout le pas, et messire Jehan d'Aubrecicourt, ainsi que il regarda, il le choisy et recongneut. Si dist: "Vecy le hérault du roy de Portingal, qui ne fut, long temps a, en ce pays. Je luy veul demander des nouvelles. «121

Im darauffolgenden Gespräch berichtet der Herold von seiner einjährigen Reise, die ihn auch nach England führte. Hier habe er den König und die verschiedenen Herren des Landes gesehen, die ihn reich gemacht hätten. Später sei er in die Bretagne übergesetzt, wo er in Nantes der Hochzeit des Herzogs mit Johanna von Navarra beiwohnte ${ }^{122}$.

Zweimal wird hier auf wenigen Zeilen erwähnt, daß der Herold Neuigkeiten zu erzählen habe. Seine Gesprächspartner erfuhren dabei nicht nur von den einzelnen Etappen seiner Reise, sondern auch von der Freigebigkeit der englischen Herren und von den Feierlichkeiten zur Hochzeit des bretonischen Herzogs.

In seiner Chronik des Konstanzer Konzils (1414-1418) liefert Ulrich Richental unter anderem eine Aufzählung aller Personen, die hier zugegen waren. Die Herolde fanden hierbei folgende Beschreibung:

Item recht herolten von allen küngrichen, die der küng waupen trügend und ir bottschaft wurben und iro herren er und wirdikait ußsprachen, si wärind cristan oder ains anders globen, die mir och diß sach seitend und ich ir och ettlichen ze huß lied und sy fragt, dero was mit knechten $x$ lvi ${ }^{123}$.

Die Herolde aus aller Herren Länder haben in Konstanz also einerseits die Sache ihrer Herren öffentlich beworben und von deren Ehren erzählt. Andererseits wurden sie von Ulrich Richental eigens in sein Haus eingeladen, um sie auszufragen.

Auch auf den bereits erwähnten alten Ritter Sarasin d'Ailly und seinen ebenso betagten Persevanten - von denen Monstrelet berichtet - ist hier noch einmal zurückzukommen:

Lequel pour lors povoit bien avoir soixante dix ans d'aage, et demouroit en ung sien chastel qu'il avoit de par sa femme [...]. Et là estoit tout malade de goutes. Néantmoins, moult voulentiers enquéroit et oroit racompter des nouvelles. Si retourna en ses jours sondit poursuivant nommé Havrenas, qu'il avoit envoyé dehors. Et estoit environ de l'aage de son maistre, et l'avoit longtemps servi. Et après sa venue l'examina; si lui demanda, messire Sarrasin, s'il sçavoit riens de la morte du roy d'Angleterre. Et il respondi que oyl, et que il l'avoit veu en la ville d'Abbeville en l'église Saint-Effren. Et lui racompta tout l'estat, et comment il estoit appareillé, assez selon qu'il est déclairé en ce présent livre ${ }^{124}$.

Abgesehen davon, daß der alte Sarasin durch seinen Persevanten von der ganzen Aufmachung des Leichenzuges des verstorbenen Königs Heinrich V. erfuhr, schien er diesen eigens ausgesandt zu haben, um Neuigkeiten zu erfahren.

121 Froissart, Chroniques, Bd. XI, S. 390.

122 Ibid., S. 391.

123 Buck (Hg.), Ulrichs von Richental Chronik, S. 183.

124 Enguerran de Monstrelet, La Chronique, Bd. IV, S. 116 f. 
Welche Attraktivität, aber auch welch vergängliche Wirkung die Erzählungen der Herolde bei ihren Zeitgenossen entfalteten, wird in der Chronik des Michel Pintoin deutlich. Nachdem dieser von den herausragenden Taten des Admirals Clignet de Brebant, des Maréchal Boucicaut und des Bastards von Bourbon 1415 gegen die Engländer vor Calais berichtete, stellt er in einem geradezu strafenden Tone fest:

laudabiliter peregerunt et actus commendabiles, dignos quoque memoria, unde certe gloriam sibi perhennem peperissent, si scriptis expeciisent mandari; se quasi proprie fame neglectores, contenti sunt clamoribus preconum triumphorum, vel echo excipienti plausus theatrales cum quanto periculo tunc usi sunt commisisse ${ }^{125}$.

In ihrer Eröffnung eines Streitgespräches zwischen einem englischen und einem französischen Herold ob der Frage, welchem der beiden Königreiche mehr Ehre zukomme, schien Dame Prudence - bei aller gebotenen Skepsis, die eine mögliche Selbstaussage der Herolde verlangt ${ }^{126}$ - demnach mit guten Recht behaupten zu können:

Beaulx seigneurs, [...] vous avez ung bel office, et que tous nobles doivent amer et priser, car a voz rappors et relacions les roys, les dames, les princes et autres grans seigneurs jugent des honneurs mondains, soit en armes, comme en assaulx, batailles, sieges, ou autrement en joustes, en tournois, en haultes et pompeuses festes et obseques. Et toutes choses faictes en grans magnificences et tendans a honneurs par vous doivent estre herauldées et publiées en divers royaumes et pays; donnez courage a plusieurs princes et nobles chevaliers de faire de haultes entreprinses par quoy il soit d'eulx longue fame et renommée, et devez dire verité en armes et departir les honneurs a qui ilz appartiennent ${ }^{127}$.

$\mathrm{Da} ß$ die Verbreitung von Berichten über Waffentaten und große Feste - hier zudem als Kern des schönen Amtes der Herolde geschildert - mit dem Neologismus »heraulder « umschrieben wird, der zudem synonym mit dem Wort »publier«, also »bekanntmachen«, »verbreiten«, gebraucht wird: Dies alles unterstreicht noch

125 Bellaguet (Hg.), Chronique du religieux, Bd. V, S. 550.

126 Die Autorenschaft ist noch nicht geklärt. Zum einen erläutert Henri Pyne, der 1870 eine englische Übersetzung des »Débat « herausgab, in einer sehr umfangreichen und detaillierten Weise eine mögliche Urheberschaft Karls von Orléans (Pyne, England and France, S. 148154). Diese Zuweisung wurde in der französischen Edition des Textes (vgl. PANNIER, MEYER [Hg.], Le débat des hérauts) jedoch durch Léopold Pannier und v. a. durch Paul Meyer, der die Arbeiten Panniers zu Ende führen, in Zweifel gezogen, meiner Ansicht nach aber anhand der falschen Argumente. Die offensichtlichen geographischen Koinzidenzen zwischen den im »Débat « gemachten Schilderungen Englands und der Gefangenschaft Herzog Karls von Orléans werden hierbei völlig außer acht gelassen (ibid., S. vii-xi). Paul Meyer hingegen hält die Autorenschaft eines Heroldes für möglich, bezeichnet diese Vermutung jedoch selbst als »une impression plutôt qu'une oppinion arrêtée« (ibid., S. xi). Die Lösung dieser spannenden Frage muß daher bis auf weiteres offenbleiben.

127 Ibid., S. 1. Für eine eingehendere Analyse in Bezug auf das Heroldswesen vgl. besonders MelviLle, Geschichte im Diskurs. Das hier wiedergegebene Zitat ist Thema eines weiteren Aufsatzes von Gert Melville, der eine ausführliche Interpretation dieser Passage zum Ausgangspunkt für einen weitreichenden Überblick über die Aufgabe, die Geschichte, vor allem aber über die soziale Funktion der Herolde nimmt: DeRs., »Un bel office«, S. 249 f. und passim. Zum Inhalt des »Débat des hérauts« vgl. darüber hinaus KRIEGER, England. 
einmal deutlich die Bedeutung der kommunikativen Rolle der Herolde wie auch vice versa die Bedeutung der Herolde für die Verbreitung von Neuigkeiten, Ruhm und Ehre.

\subsubsection{Das literarische Wirken der Herolde}

Wenn die Herolde auch in überwiegendem Maße auch mündlich wirkten, so haben sie dennoch eine Fülle von schriftlichen Zeugnissen hinterlassen, welche bisher kaum eine angemessene Würdigung erfahren haben. Diese bestätigen in Inhalt wie Umfang eindrucksvoll die gemachten Aussagen ${ }^{128}$. Das Euvre der Herolde erstreckt sich dabei über ein breites Feld: von Totenklagen und Ehrenreden über Chroniken, Turnier-, Obsequien- und Länderberichte, Wappenbücher und Genealogien bis hin zu panegyrischen, aber auch politischen Gelegenheitsdichtungen.

Ein eingehenderes Verständnis für die Breite des literarischen Schaffens der Herolde und deren sich darin widerspiegelnden Interessen ist Ziel der folgenden Aufzählung. Sie soll einen Überblick vermitteln über die Breite und Vielfalt der bisher bekannten Quellen, wobei ein besonderes Gewicht auf Beispiele französischer und englischer Provenienz gelegt wurde, wenn auch wesentliche Texte niederrheinischen und deutschen Ursprungs Erwähnung finden ${ }^{129}$.

Die ältesten bekannten Beispiele des literarischen Wirkens der Herolde nämlich sind aus dem deutschsprachigen Raum überliefert. Sie stammen aus der Feder des österreichischen Herolds und Spruchdichters Peter Suchenwirt, dessen Schaffensphase zwischen 1347/49 und $1395 \operatorname{lag}^{130}$. Zu seinem Werk zählen neben seinen berühmten Totenklagen und Preisreden auch mehrere geistliche, vor allem aber didaktische Gedichte, die mitunter aktuelle Bezüge besaßen und meist deutlich von Zeitenklage und Adelslehre durchdrungen waren ${ }^{131}$.

Ebenfalls aus dem Ende des 14. Jahrhunderts datiert auch die erste Chronik eines Herolds, hier noch als Reimchronik, in der Chandos über die Kriegszüge des Schwarzen Prinzen zwischen 1346 und 1376 in Frankreich und Kastilien berich-

$128 \mathrm{Zu}$ den literarischen Aktivitäten der Herolde vgl. v. a. LESTER, Fifteenth-Century English Heraldic Narrative; Ders., Literary Activity; StANesco, Héraut d'armes, und VAN ANROOIJ, Spiegel van ridderschap, S. 43-55.

129 Hierbei sollen aber nur jene Texte Erwähnung finden, denen definitiv auch ein Herold als Autor zuzuschreiben ist, die Zuweisung also nicht auf bloßen Indizien beruht, die u. a. Godfrey Allen Lester mehrfach bemüht, vgl. z. B. LESTER, Fifteenth-Century English Heraldic Narrative, S. 203 und DeRs., Literary Activity, S. 227.

130 Zu Peter Suchenwirt vgl. Weber, Peter Suchenwirt; CaIn-van D'Elden, Peter Suchenwirt als Herold; DiES., The Ehrenreden; Dies., Peter Suchenwirt and Heraldic Poetry; NolTE, »Lauda post mortem«; BRINKER, »Von manigen helden gute tat«. Eine Übersicht über die politische Lyrik Suchenwirts findet sich bei MüLLER, Untersuchungen, S. 190-201. Ediert sind seine Werke in: PrIMISSER (Hg.), Peter Suchenwirt's Werke, und FrIESS (Hg.), Fünf unedierte Ehrenreden Suchenwirts.

131 Vgl. dazu ausführlicher auch vAN ANROOIJ, Spiegel van ridderschap, S. 190-193. 
tet ${ }^{132}$. Ihr folgt wenig später die des Wigand von Marburg zur Geschichte des Deutschen Ordens zwischen 1311 und 1394, dessen Hochmeisters Herold er war ${ }^{133}$. Im Mittelpunkt seiner Ausführungen standen dabei die ritterlichen Erlebnisse der zahlreichen Preußenfahrer, die aus ganz Europa anreisten, um an der Seite des Ordens gegen die Heiden zu kämpfen ${ }^{134}$.

Aus dem Beginn des 15. Jahrhunderts stammen zwei historiographische Kompilationen aus der Feder des Claes Heynenzoon, Herold unter dem Namen Gelre und später Beyeren. Neben seinem berühmten Wappenbuch trug er unter anderem eine Weltchronik und eine Geschichte Hollands zusammen ${ }^{135}$. Auch von ihm sind zahlreiche Ehrenreden überliefert, die sich ebenfalls nicht nur der Memoria der teils schon lange verstorbenen Ritter widmeten, sondern der nachkommenden Ritterschaft zugleich Vorbilder für ein ehrenvolles und würdiges Leben aufzeigen wollten. Aus der Mitte des Jahrhunderts datieren dann die beiden wohl berühmtesten von Herolden verfaßten Chroniken, die sich beide mit den Ereignissen der ersten Hälfte des 15. Jahrhunderts auseinandersetzen: die Chroniken von Jean Lefèvre (Wappenkönig Toison d'or) ${ }^{136}$ und von Gilles Le Bouvier (Herold Berry), letzterer unter Karl VII. lange als premier hérault genannt und seit 1451 schließlich in die Position des obersten französischen Wappenkönigs Montjoye aufgerückt ${ }^{137}$.

Die beiden Chroniken waren jedoch nur die bekanntesten Werke dieser Herolde, nicht aber deren einzige. Während Berry unter anderem auch eine Beschreibung der verschiedenen Länder Europas und des Orients sowie einen Bericht über die Wiedereroberung der Normandie verfaßte ${ }^{138}$, erläuterte Toison d'or die Regeln für Wappenminderungen (Brisuren) ${ }^{139}$ und berichtete von den Taten des Jacques de Lalaing, eines der gefeiertsten Ritter seiner Zeit. Sehr ausführlich geht der Herold dabei auf den von Jacques de Lalaing veranstalteten »Pas de la

132 Das 1385 entstandene Werk wurde u. a. ediert von Lodge, Pope (Hg.), The Life of the Black Prince. Vgl. darüber hinaus BARBER, The life and campaigns.

133 Vgl. van AnrooIJ, Spiegel van ridderschap, S. 30, und PARAVICINI, Preußenreisen, Bd. I, S. 14. Weiterhin sind zu nennen: Boockmann, Geschichtsschreibung des Deutschen Ordens im Mittelalter, und Boockmann, Die Geschichtsschreibung des Deutschen Ordens - Gattungsfragen.

134 Von dem umfassenden volkssprachlichen Werk sind leider nur noch Bruchstücke bzw. schlechte Übersetzungen ins Latein und Paraphrasen erhalten, vgl. HIRSCH, TOEPPEN, StREHLKe (Hg.), Scriptores Rerum Prussicarum, Bd. II, S. 429-662, 804-806; ibid., Bd. IV, S. 1-8 und Bd. VI, S. 44-49. Zu den Preußenreisen an sich vgl. grundlegend PARAVICINI, Preußenreisen.

135 Vgl. VerbiJ-Schillings, Beeldvorming in Holland. Zum Wappenbuch vgl. AdAM-Even u. a. (Hg.), L'armorial universel, sowie dessen Faksimile-Ausgabe Gelre B.R. Ms 15652-56. 136 Vgl. Morand (Hg.), Chronique.

137 Zur Karriere des Berry vgl. Melville, »Roy d'armes«, v. a. S. 598-600. Seine Chronik wurde ediert von Courteault, CELIER (Hg.), Les chroniques.

138 Vgl. Gilles le Bouvier, dit Berry, Recrouvement de Normandie, in: Hellot (Hg.), Chroniques, S. 99-169.

139 Zur Überlieferung siehe unten, Anhang, Kap. 6.2.3.1. 
Fontaine de pleurs« ein, in dessen Verlauf er teilweise selbst als Turnierrichter auftrat ${ }^{140}$.

Damit ist ein literarisches Genre angesprochen, auf welches sich die Herolde ganz besonders verstanden: die Berichte von großen Taten und Ereignissen, von Turnieren und Feierlichkeiten. Die Begebenheiten um den von Philipp de Lalaing, eines Neffen des eben genannten Lalaing, durchgeführten »Pas du perron fée« wurden gleich von zwei Herolden schriftlich festgehalten. Sowohl der burgundische Herold Limbourg als auch der in englischen Diensten stehende Chestre berichteten von dieser Veranstaltung ${ }^{141}$. Von Chestre ist zudem ein weiterer Turnierreport zur »Emprise de la Fleur de souvenance« erhalten, einem Zweikampf zwischen dem Engländer Anthony Woodville, Lord Scales und Antoine, dem Großen Bastard von Burgund, bei dem Chestre selbst die Herausforderung überbrachte ${ }^{142}$.

Weitere Turnierberichte stammen vom obersten englischen Wappenkönig Garter zum »Pas de l'Arbre d'or « anläßlich der Hochzeit Karls des Kühnen mit Margarete von York im Jahre 1468143; von William Ballard, Wappenkönig March, zum Turnier anläßlich der Hochzeit des Herzogs von York im Jahre 1478144; von einem Herold Orléans zu dem berühmten Turnier von Sandricourt im Jahre 1493145; wie auch aus der Feder des Wappenkönigs Montjoye zu den Tjosten anläßlich des Einzuges der Königsbraut Maria von England 1514 in Paris 146.

Den feierlichen Einzug des Herzogs Karl des Kühnen wie das weitere Zeremoniell des 1473 in Valenciennes abgehaltenen Ordensfestes des Ordens vom Goldenen Vlies wiederum beschrieb der burgundische Herold Charolais, Wappenmarschall von Brabant. Der Text beginnt hier - wohl auch stellvertretend für alle anderen Berichte - mit den Worten:

Pour ce que plusieurs personnes desirent de sçavoir et oyr racompter ou voir par escript toutes choses faictes de grant excellence, moy, Charolois, herault d'armes de mondit seigneur de Bourgogne et marissal d'armes de la ducé de Brabant, me suis entretenus de mettre par escript au plus pres de la verité tout ce qui a esté fait touchant les serimonies et grans triumphes qui pour la noble ordre de la Thoison d'or on estre faictes et tenues en ceste ville de Vallenchienes ${ }^{147}$.

140 Vgl. Morand (Hg.), Epitre de Jean Lefèvre. Zum »Pas de la Fontaine de pleurs« wie zur Rolle des Toison d'or hierbei vgl. insbesondere MelviLLE, Der Held.

$141 \mathrm{Vgl}$. zum einen Limbourg, Pas du perron fée, und zum anderen den Bericht Chestres unter anderem in London, BL, Harley 48, fol. 53v-77v, wo es am Ende heißt: comme il est acoustumé a faire a l'ostel de ces princes, ce fitz Chestre le herault.

142 Vgl. London, BL, Lansdowne 285, fol. 29-42.

143 So zumindest geht es aus einem Bericht zu dieser Hochzeit hervor, wo der Autor zu den dazugehörigen Turnierveranstaltungen nichts weiter ausführen mag, weil Gart' the Kyng of Armys hathe it in Frenche, and for that cause I leve to wryitt (BENTLEY [Hg.], Excerpta Historica, S. 238).

144 Vgl. Black (Hg.), Illustrations of Ancient State, S. 131. Vgl. auch Wagner, The Records, S. 8 .

145 Vgl. Orléans, Le Pas d'armes de Sandricourt.

146 Vgl. Paris, BnF, fr. 5103.

147 Valenciennes, Bm, 776 (581), fol. 62-71, hier fol. 62r. 
Berichte der Herolde sind weiterhin zu Taufen ${ }^{148}$ wie Obsequien großer Herren erhalten. Der bereits genannte Herold Chestre berichtete beispielsweise über die Bestattung Richards, Herzog von York und Vater des englischen Königs Eduard IV. ${ }^{149}$, wobei er seinen Ausführungen ein Epitaph bzw. eine kurze Preisrede anfügte ${ }^{150}$. Der wohl bekannteste Obsequienbericht eines Herolds stammt sicher aber von Pierre Choque, dem Herold Bretagne, in welchem er die Feierlichkeiten zu den Bestattungen seiner verstorbenen Herrin Anne de Bretagne im Jahre 1514 schildert ${ }^{151}$. In einer größeren Stückzahl kopiert, wurde er an den europäischen Hochadel verschenkt, so daß er noch heute in zahlreichen Ausfertigungen überliefert ist. Ein weiteres Großereignis, von dem Pierre Choque berichtete, lag zu diesem Zeitpunkt bereits einige Jahre zurück. In zwei getrennten Darstellungen legte er einen Rapport von den unterschiedlichen Etappen der Ereignisse um die Hochzeitsfeierlichkeiten der Anne de Foix mit dem böhmischen und ungarischen König Ladislaus II. ab, die er selbst auf dem Weg zu ihrem zukünftigen Gemahl begleitete ${ }^{152}$. Nicht anders war dies über siebzig Jahre zuvor, als der Wappenkönig von Flandern von seiner Mission nach Portugal berichtete, von wo er 1428 die zukünftige Frau des Herzogs nach Burgund begleitete ${ }^{153}$.

$\mathrm{Zu}$ den Berichten über höfische Ereignisse sind letztlich auch die Aufzeichnungen des Persevanten Bluemantle aus den Jahren 1471/72 zu zählen, in denen er verschiedene Ereignisse am Hof Edwards IV. festhält. So seine eigene Entsendung an den Hof Karls des Kühnen nach Burgund oder den Empfang Ludwigs von Brügge in England, in dessen Haus Edward einige Zeit zuvor noch Asyl fand ${ }^{154}$.

Aber nicht nur ritterliche und höfische Ereignisse ließen die Herolde zur Feder greifen. Ihre umfangreichen Erfahrungen, welche sie auf ihren zahllosen Reisen durch Europa und darüber hinaus gesammelt hatten, faßten sie ebenso schriftlich

148 Vgl. beispielsweise den Bericht des Jean de Tournai, Wappenkönig Bonnes Nouvelles, über die Taufe des Emmanuel-Philibert von Savoyen im Jahre 1528, Bonnes Nouvelles, Récit du baptême.

149 London, BL Harley 48, fol. 78r-81r und fol. 139r-142r: La fourme et la magniere de l'anterrement du tres hault et puissant et tres excellent prince Richart, duc de Jork, pere du roy nostre souverain seigneur Edouart le quart. Explicit: Chestre le Herault. Et donna ce jour a l'office d'armez sans leurs robes et chapperon et sans leurs desspens xx $£$. Dieu envoi l'ame, Amen.

150 Ediert bei Wright (Hg.), Political Poems, Bd. II, S. 256 f.

151 Vgl. Merlet, Gombert (Hg.), Récit des funérailles. Daß die Herolde auch im 16. Jahrhundert noch Obsequienberichte verfaßten, dazu vgl. u. a. ROYER (Hg.), Relation inédite.

152 Vgl. Le Roux DE Lincy (Hg.), Discours des cérémonies, sowie Ders. (Hg.), Discours sur la réception.

153 Vgl. Besançon, Bm, Coll. Chiflet 65, fol. 80r-106r: Verbal du voyage de Portugal, qui se faist de par feu monseigneur le bon duc Philippe de Bourgoigne, en l'an mil quatre cens et vingt huict, pour amener en ses pays de perdeça madame Elisabeth, infant de Portugal, sa compaigne, escrits par Flandres, roy d'armes du bon duc Philippe de Bourgogne, extraict des registres de la Chambre des comptes de Brabant.

154 Vgl. Kennedy, Chronicles, Kap. 21, Nr. 74 und die Edition bei KInGSFORD, English Historical Literature, S. 379-388. 
zusammen. Die Länderbeschreibungen des Herolds Berry wurden bereits genannt ${ }^{155}$. Eine andere Übersicht über die Länder Europas stammt von einem portugiesischen Herold, der diese bereits um 1416 - und dies ist ein Unikum - in Latein verfaßte ${ }^{156}$.

Wurden hier bereits die Darstellungen der einzelnen Länder durch heraldische Übersichten eingeleitet, so liegt die Verbindung zu den Wappenbüchern der $\mathrm{He}$ rolde nicht fern. Als deren bekannteste seien jene des Herolds Gelre ${ }^{157}$ und der Herolde des französischen Königs, des Navarra ${ }^{158}$ und des Berry ${ }^{159}$ genannt. Daß es sich dabei aber nicht nur um einfache Aufzählungen verschiedener Wappen handeln mußte, dies belegen unter anderem die Wappenbücher des Guillaume de Revel und des englischen Wappenkönigs Garter, John Wrythe. Ersterer, unter dem Namen Auvergne im Dienste des Herzogs Karl I. von Bourbon und der Auvergne $^{160}$, nahm neben den Wappen auch zahlreiche Stadt- und Schloßansichten mit auf, wodurch der Adel und das Land geradezu plastisch aufgeführt wurden. Das Wappenbuch des John Wrythe hingegen, im späten 15. Jahrhundert entstanden und die Wappen aller Ritter des Hosenbandordens beinhaltend, zeichnet sich dadurch aus, daß mehrere der Wappen von kurzen biographischen Notizen zu deren Besitzern begleitet wurden ${ }^{161}$.

Um eine Verbindung aus der Blasonierung des Familienwappens und einer kurzen Familiengeschichte handelt es sich bei dem 196 Verse umfassenden »Blason de Lalaing « des Herolds Luxembourg, den dieser 1509 den noch jungen Brüdern Jacques und François de Lalaing zueignete, nicht ohne diese deutlich zu ermahnen:

Tres redoubtez et honnoures signeurs,

Souviengne vous dont este descendus.

Des nobles faitz de vos antecesseurs,

Dont le surnoms portez, ayez les meurs.

Ayes memoire que vous estez venus,

Par pere et mere, de cheus dont jamais nulz.

Trouvé ne fu ayant nul fer qui loche,

Mais tous sont mors CHEVALIERS SANS REPROCHE ${ }^{162}$.

155 Daß die Länderbeschreibung Berrys weit weniger auf dessen Reiseerfahrungen beruhte, als bisher landläufig angenommen wird, dazu siehe ausführlich noch unten, Kap. 4.3.4.4.

156 Ediert von NAScimento (Hg.), Livro de Arautos. Siehe zudem GodinHO, La description, sowie PARAVICINI, Signes et couleurs.

157 Vgl. oben, Anm. 135.

158 Vgl. DouËT D’ARCQ (Hg.), Armorial de France, sowie ADAM-Even, Études d'héraldique médiévale.

159 Vgl. Vallet de Viriville (Hg.), Armorial de France.

160 Die Zuordnung unter Karl I. resultiert unter anderem aus der Datierung auf die Zeit um 1455 durch Pastoureau, Traité d'héraldique, S. 225. Eine spätere Datierung zwischen 1458 und 1460 hingegen ist angegeben bei TraVERS, Ch. Casati de Casatis. Die Handschrift ist unvollendet und findet sich in den Beständen der Pariser Nationalbibliothek unter der Signatur Paris, BnF, fr. 22297. Sie wurde ediert von FouRnIER, Châteaux, villages et villes, sowie Boos, L'armorial d'Auvergne.

161 Vgl. Wagner, Catalogue, S. xxv und 122-124.

162 Brassart, Blason de Lalaing, Bd. I, S. 12. 
Daß auch die Abfassung von Genealogien zu den Beschäftigungen der Herolde zählen konnte, dafür steht darüber hinaus eine kurze genealogische Familienchronik zu Peter I. von Luxemburg, Graf von Saint-Pol, und dessen Frau Marguerite des Baux. In einer der Überlieferungen heißt es am Ende, der Autor habe diese für die Nachfahren der beiden verfaßt, die nun deren Namen trügen, comme il appartient a faire a homme de notre office d'armes ${ }^{163}$.

$\mathrm{Da}$ aus diesem Genre jedoch nur wenige Texte überliefert sind, mag seine Ursache auch darin haben, daß derlei Genealogien als rein mündliche Texte entstanden sein konnten. Auch für ein fortlaufendes Wirken der Herolde im Sinne von Sprechern und Spruchdichtern scheint es für den französischen Raum zumindest einzelne Belege zu geben. So ist zum Beispiel eine ganze Sammlung von Gedichten des Engherant le Franc, Stadtherold von Valenciennes, erhalten, die er in den 1460er Jahren anläßlich verschiedener Hochzeiten und für die confrérie des Damoiseaux verfaßte ${ }^{164}$. Und auch auf den berühmten Pierre Choque ist an dieser Stelle noch einmal zurückzukommen. Denn neben seinen oben erwähnten Hochzeits- und Obsequienberichten ist von diesem auch die Übersetzung eines Gedichtes von Guillaume Brie zum Untergang der »Cordelière « überliefert, des Schiffes, auf dem der Herold noch wenige Jahre zuvor Philipp von Ravenstein gegen die Türken begleitete. Er selbst dichtete ein Rondeau zu Ehren des Kapitäns, wie auch ein Epitaph in zehn Versen. Und zu den Totenfeierlichkeiten seiner Herrin Anne de Bretagne verfaßte er nicht nur den späteren schriftlichen Bericht, sondern auch einen chant royal ${ }^{165}$.

Faßt man die schriftlichen Hinterlassenschaften der Herolde zusammen, so eröffnet sich ein breites Spektrum an Genres und Inhalten, in dessen Hintergrund dennoch fast immer die gleichen Interessen standen: herausragende Ereignisse, Personen und Ehre. Dies war bei den Ehrenreden, Chroniken, Wappenbüchern und Genealogien nicht anders als bei den diversen Berichten zu ritterlichen und höfischen Ereignissen, an denen die Herolde meist auch selbst teilhatten ${ }^{166}$. Wäh-

163 Paris, BnF, fr. 5229, fol. 39r-41v, hier fol. 41v.

164 Vgl. LaCROIX (Hg.), Ditiers.

165 Vgl. JAL, Marie-La-Cordelière, mit einer Edition des Rondeau und des Epitaphs für Hervé de Portmoguer, sowie des »Chant Royal en l'Honneur d'Anne de Bretagne«. Seine Übersetzung des Gedichtes »La Cordelière« ist in der Handschrift Paris, BnF, fr. 1672 überliefert.

166 Die Wappenbücher konnten in diesem Sinne ja nicht nur als Hilfsmittel zur Identifizierung der Wappen verstanden werden, sondern - in ihrer symbolischen Funktion - auch als imaginäre Adelsversammlungen. Vgl. hierzu z. B. den Text des Wappenkönigs Hermann von Brüninghausen, zu dem von ihm zusammengestellten Wappenbuch des Hubertusordens des Herzogs von Jülich und Berg: Dit heraltz bouch ich herman eyn tornyrkunde heralt gemacht ind geordenert han van bete myns genedichen lieuen heren hertzoge van golche ind van den berchge omb dej orden wylle ind jn oren bewissen sal syn syrde jn herkomst jn setzen sal lassen omb alwegen for eym jnd syn naekomlincken altzit zo fynden jn wer an myn genedigen heren ind dj syn genaden darzo ordenert den orden jn er des hilgen synt huppertz in dj broederscheft zo komen (zitiert nach BERCHEM, Herolde, S. 136 und 139). Zu Hermann von Brüninghausen vgl. SEGGERN, Hermann von Brüninghausen. 
rend die Verfassung und Aufführung mündlicher Texte auch noch zu Beginn des 16. Jahrhunderts eine wichtige Rolle für das Heroldswesen zu spielen schien, ist zum anderen eine fortschreitende Verschriftlichung ihres Amtes zu beobachten, zumal bei den Herolden im fürstlichen Dienst ${ }^{167}$. Für nichts anderes stehen gerade die stärker technisch abgefaßten Berichte von großen Ereignissen und ritterlichen Taten, welche deren mündliche Propagierung zumindest ergänzten. Daß dabei nicht allein die Bewahrungsfunktion der Schrift und damit ihr ewiges Gedächtnis im Vordergrund stand, sondern den Herolden auch an einer schnellen und weiten Verbreitung dieser Texte und Inhalte gelegen war, dafür scheint das englische Beispiel zu sprechen. Hier verfaßten die Herolde ihre Berichte seit der zweiten Hälfte des 15. Jahrhunderts statt in der französischen Hofsprache zunehmend in Englisch, in der Absicht, damit eine noch breitere Öffentlichkeit erreichen zu können ${ }^{168}$.

Geschichte, Aufgaben und Wirken der Herolde, deren anhaltende Verbindung zu den Spielleuten, ihre Rolle als öffentliche Kommunikatoren von Ansehen und Ehre und die zunehmende Verschriftlichung ihres Amtes: Vor diesem Panorama gilt es, die hier zur Untersuchung stehenden Heroldskompendien einzuordnen.

\subsection{Forschungsstand}

$\mathrm{Zu}$ den Kompendien der Herolde ist bis jetzt so gut wie nichts bekannt. Obwohl deren Inhalte innerhalb der Forschung zum Heroldswesen des öfteren als Quelle Verwendung fanden, haben sie als eigenständiges Phänomen bisher fast keine Beachtung gefunden.

Dabei erschien die erste Edition eines Heroldskompendiums, wenn auch unkritisch und fehlerhaft, bereits im Jahre 1867. Hier handelt es sich um eine Transkription der Handschrift Paris, BnF, fr. 387, des »Kompendiums des Herolds Sicile« also, die durch Ferdinand Roland besorgt und von der Société des bibliophiles belges zu Druck gebrachte wurde ${ }^{169}$. Abgesehen von einer kurzen Handschriftenbeschreibung und einigen Spekulationen zur Person des Autors, blieb der Text hierbei editorisch wie inhaltlich unkommentiert. Dieser einzigen integralen Edition eines Heroldskompendiums folgten über ein Jahrhundert später nur zwei Teileditionen, die aber zumindest einige der in den Heroldskompendien überlieferten Texte zugänglich machten.

Deren erste wurde im Jahre 1983 durch Alan Manning unternommen ${ }^{170}$. Unter der Bezeichnung »Argentaye Tract« edierte er den ersten Traktat der Pariser Handschrift BnF, fr. 11464, den man getrost als einen kompilatorischen Flickenteppich bezeichnen kann. Eingewoben sind unter anderem drei der in den He-

167 Vgl. hierzu auch MelviLLE, »Un bel office«, S. $310 \mathrm{f}$.

168 Vgl. LESTER, Fifteenth-Century English Heraldic Narrative, S. 203.

169 Vgl. Roland (Hg.), Parties inédites.

$170 \mathrm{Vgl}$. Manning (Hg.), The Argentaye Tract. 
roldskompendien am weitesten verbreiteten Texte, wenn auch jeweils in leicht modifizierter Form ${ }^{171}$. Jedoch lag das Interesse des Herausgebers vor allem auf dem von heraldischen Inhalten bestimmten ersten Text der Kompilation, den er mehr oder minder nur als Wappentraktat verstand und nicht in das weitere Umfeld der Handschrift einzuordnen wußte. Die anderen Texte zog er daher allein für Datierungsfragen heran ${ }^{172}$. Die enge inhaltliche Verbindung des vorliegenden Traktates mit den anderen Texten der Handschrift blieb unberücksichtigt ${ }^{173}$.

Die zweite Teiledition stammt von Luuk A. J. R. Houwen und Martin Gosman (1991) und gibt, wenn hier auch nur als ein einzelner beschrieben, gleich mehrere Traktate eines im Londoner College of Arms überlieferten Heroldskompendiums englischer Provenienz wieder ${ }^{174}$.

Obwohl damit zumindest eines der Heroldskompendien bereits seit der zweiten Hälfte des 19. Jahrhunderts auch in gedruckter Form der Forschung zugänglich war, folgte daraus keinerlei Auseinandersetzung mit diesem oder mit der Quellengruppe allgemein. Wenn schon nicht als eigenständiges Phänomen untersucht, so wurden sie seit der Mitte des letzten Jahrhunderts mit den Arbeiten von Anthony Richard Wagner doch wenigstens als Quelle genutzt. Autor zweier noch immer wesentlicher Monographien zum Heroldswesen, hat dieser die Forschungen zum office d'armes im eigentlichen Sinne erst initiiert. Doch auch wenn er in seinen Arbeiten mehrfach auf die Texte der Heroldskompendien zurückgreift ${ }^{175}$, kommt es nirgends auch nur ansatzweise zu einer Auseinandersetzung mit diesen als Quelle selbst. Die Textsammlung des Herolds Sicile wird hier schlicht als ein $»$ treatise on heralds by a herald « 176 beschrieben, ohne in irgendeiner Form auf deren kompilatorischen Charakter, vor allem aber auf deren Entstehungshintergrund und Quellenwert einzugehen.

Die ganze inhaltliche Breite der in den Heroldskompendien enthaltenen Traktate wurde überhaupt erst von Paul Adam-Even (1957) in seinem Überblick über

171 Siehe hierzu noch unten, Kap. 3.2.9.

$172 \mathrm{Zu}$ dieser deutlichen heraldischen Ausrichtung vgl. bereits den ersten Abschnitt der Einleitung, welcher mit »Heraldry eternal« (S. 3) überschrieben ist, von der anhaltenden Begeisterung für das Wappenwesen spricht und auf neugegründete Heraldik-Clubs und Gesellschaften verweist.

173 Auch die Kommentierung des Textes ist aufgrund der Arbeitsweise des Herausgebers nur eingeschränkt zu gebrauchen. So führt er unter anderem in einer Liste von Blasonierungstraktaten, die er, wie er selbst schreibt, »closely examined « habe, den »Créquier-Traktat « unter dem Namen »Hongrie-Tract « auf (S. 9). Denn dieser stamme vom Wappenkönig Hongrie, der sich, und dies sei eine beachtenswerte Ausnahme, im Prolog des Traktates selbst nenne. Daß dies so nicht zutreffen kann, dazu siehe unten, S. 86.

174 Vgl. Houwen, Gosman, Un traite d'héraldique. Hier enthalten sind: der »Traktat über die fünf militärischen Ämter und die Aufgaben der Herolde«; eine für den englischen Gebrauch umgearbeitete Version der »Anleitung zur Durchführung einer Legation durch die Herolde « und der »Farbentraktat «.

175 Vgl. z. B. WAGNER, Heralds and Heraldry, S. 38 f., 41 f. und 56, sowie Ders., Heralds of England, S. 40-47 und S. 72-75.

176 WAGNER, Heralds and Heraldry, S. 41. 
die militärische Funktion der Herolde erwähnt, wenn er wie folgt in die literarische Tätigkeit der Herolde einführt:

Les hérauts ont écrit nombre de traités destinés à l'instruction des poursuivants [...]; les uns sont des cérémoniaux détaillant l'ordonnance des tournois, gages de batailles, obsèques et autres fêtes; les autres des traités de blason, souvent complétés par des armoriaux qui en sont, pour ainsi dire, l'illustration; les derniers enfin exposent les droits et usages de la profession ${ }^{177}$.

Er verweist also auf die verschiedenen Lehrtraktate aus der Feder der Herolde, welche der Unterweisung ihrer Nachfolger dienend entweder von ritterlichen Zeremonien wie Turnieren, gerichtlichen Zweikämpfen oder Obsequien handeln, oder Abhandlungen zur Wappenblasonierung sowie zu den Rechten und Bräuchen des Heroldswesens beinhalten konnten. Zu einer näheren Charakterisierung der Kompilation des Herolds Sicile, auf deren Texte er sich hauptsächlich stützt, kommt es aber auch hier nicht. Vielmehr spricht er nur von den »opuscules héraldiques «178, die Sicile neben Blasonierungstraktaten und Wappenbüchern hinterlassen habe.

Als eigenständiges Phänomen zum ersten Mal formuliert wurden die Heroldskompendien, wohl eher ungewollt, von dem Heraldiker Jean-Bernard de Vaivre (1972). Auf deren kompilatorischen Charakter aufmerksam machend und die charakteristischen Grundzüge ihrer Überlieferung sehr wohl beschreibend, verweigert er ihnen daraufhin aber jegliches Interesse. Sein Kommentar zum Quellenwert der Heroldskompendien ist dabei von einem eigenen Verständnis geprägt:

Ces traités n'ont, en France, guère été exploités jusqu'à maintenant, car il faut bien reconnaître que la plupart ne sont que des copies ou des variantes de textes sans grand intérêt, où les hérauts ne manquaient pas de faire remonter l'origine de leur charge à Alexandre le Grand et à Jules César ${ }^{179}$.

Als eigenständiges Phänomen tatsächlich wahrgenommen wurden die Heroldskompendien denn auch erst in einem kurzen Beitrag von Philippe Contamine (1988), den er für den »Grundriß der romanischen Literaturen des Mittelalters « zu den Kriegs-, Jagd-, Blasonierungs- und Rittertraktaten des Spätmittelalters verfaßte $^{180}$. Hier heißt es, daß sich die Herolde mit der Institutionalisierung ihres Amtes und der Vervielfältigung ihrer Aufgaben im 15. Jahrhundert gleichsam zu »véritables écrivains «181 entwickelt hätten, welche nicht nur Chroniken und Wappenbücher verfaßten,

mais encore ils exposèrent dans des traités didactiques les principes de la science des armoiries. Peut-être malgré tout le principal intérêt des manuscrits où se trouvent ces traités tient à ce qu'ils sont souvent accompagnés de morceaux choisis où s'exprime la menue monnaie de la culture nobiliaire 182 .

177 ADAM-Even, Les fonctions militaires, S. 5.

178 Ibid.

179 VAIVRE, Trois couronnes, S. 31.

180 CONTAMINE, Traités de guerre.

181 Ibid., S. 364.

182 Ibid. 
Philippe Contamine faßt damit das Interesse dieser Kompendien weitaus breiter als einzig auf die darin enthaltenen Blasonierungstraktate. Zugleich verdeutlicht er den Wert dieser Kompilationen, deren Zusammensetzung er an einem Beispiel demonstriert, für das Verständnis der adeligen Kultur, auch wenn er die hier enthaltenen Inhalte eher als »Kleinkram« der adeligen Kultur bezeichnet.

Eine ausführliche Charakterisierung, vor allem aber eine erste Deutung haben die Heroldskompendien bisher allein durch Gert Melville erfahren. Erst hier fanden sie ihren Weg auch in die Geschichte des Heroldswesens. Fachenzyklopädien, Lehrbücher und Heroldsspiegel in einem, beschreibt Gert Melville die vorliegenden Handschriften als ein eigenständiges Quellencorpus ${ }^{183}$, das Normen vermitteln und Aufgabenbereiche auflisten und diese auch entsprechend veranschaulichen konnte. Deren weitgefaßten Inhalt, der sich von Abhandlungen über den Adel und Beschreibungen des höfischen Zeremoniells über Texte zum Kriegs- und Turnierrecht, Briefsteller, Krönungsregeln, Länderkunden und Eidesformeln bis hin zu Anweisungen zur Ausbildung von Herolden, Katalogen von Heroldstugenden, -pflichten und -privilegien und ausführlichen Darlegungen über die Geschichte des Heroldswesens erstrecke, charakterisiert er hierbei als »le savoir nécessaire que l'on devait posséder sur l'essence de la noblesse, les divisions politiques des pays, les offices, les cérémonies, les tournois, les guerres, etc. «184.

Von ihren Kompilatoren immer wieder neu zusammengesetzt, versteht Gert Melville diese Kompendien dabei vornehmlich als berufsbezogene Wissenssammlungen, die für den praktischen Gebrauch der Herolde gedacht waren. Doch macht er daneben auch auf Überlieferungen in Form von Prunkcodices aufmerksam. Als Beispiele einer regelrechten »Öffentlichkeitsarbeit« des Heroldswesens verstanden, sollten diese bei den großen Herren »um Sympathie und Verständnis werben für die eigentlichen Ziele des bel office und zeigen, daß sie identisch waren mit den ihrigen $\ll 185$.

Das Aufkommen dieser (vornehmlichen) Gebrauchshandschriften bewertet er als einen auffälligen Beleg für den praktischen Bedarf an derlei Wissenssammlungen im Heroldsamt. Dabei stellt er einen direkten Zusammenhang zu der historischen Entwicklung des office d'armes her und beschreibt die Kodifizierung des Aufgabenspektrums in den Hand- und Lehrbüchern des Heroldswesens als einen Teil der Institutionalisierung des Amtes ${ }^{186}$.

Gert Melville hat damit eine erste und grundlegende Beschreibung der Heroldskompendien geliefert, die es auch vermag, für den Umgang mit diesen und den darin enthaltenen Texten zu sensibilisieren. Doch hat die bis dahin übliche, unkritische Verwendung der hier eingefaßten Inhalte längst Spuren hinterlassen.

183 Zur Charakterisierung der Heroldskompendien bei Gert Melville vgl. DeRs., Hérauts et héros, S. 88; Ders., Brief, S. 72f.; Ders., Herkommen, hier S. 47 f. und Ders., »Un bel office «, S. 310.

184 Ders., Hérauts et héros, S. 88.

185 DERS., »Un bel office«, S. 310.

186 Ibid., S. 293. 
Die auftretenden Schwierigkeiten und Fehleinschätzungen rühren dabei vor allem von zwei Problemfeldern her: dem fehlenden Bewußtsein für den kompilatorischen Charakter der Kompendien, zumal was die Autorenzuweisungen für einzelne Traktate wie für die Handschriften als Ganzes betrifft. Und in der unreflektierten Übernahme von Aussagen aus den Texten, ohne daß der Quellenwert der Heroldskompendien vorher jemals kritisch hinterfragt worden wäre.

Auf letzteres hat jedoch auch Gert Melville bisher nur am Rande verwiesen, wenn er die Heroldskompendien als veritable Heroldsspiegel »sous une forme certainement idéalisée, mais néanmoins très instructive « beschrieb ${ }^{187}$. Dieser hier mit eingedachte, zuweilen idealisierende Charakter dieser Texte wurde hingegen von Anthony Richard Wagner gänzlich außer acht gelassen. So referiert er an einer Stelle den Inhalt der Gründungsakte der Vereinigung der französischen Herolde von 1407 sowie der sich anschließenden Suppliken der Herolde mit all den darin enthaltenen Forderungen, ohne dabei nur im geringsten auch die Chancen für deren Umsetzung zu hinterfragen. Diese stark normativ geprägten Texte erhalten in seiner Darstellung damit den Charakter des Faktischen, was Godfrey Allen Lester, diese Ausführungen zitierend, wiederum so in seine eigenen Arbeiten übernimmt: »Moreover, a properly qualified herald would have the appropriate writing skills, for even the lowliest poursuivant, it was urged, should be >a clever young man, who is a clerk, and under twenty five or thereabouts $\ll \ll 188$.

Was hier so sicher ins Leben gesetzt scheint, ist dabei nichts anderes als der Inhalt der Bittschriften der Herolde, in denen sie unter starker Bemühung antiker Autoritäten und legendenhafter Herkunftsgeschichten sich überhaupt um die Festschreibung derlei Regeln bemühten.

Neben dem fehlenden Bewußtsein für den spezifischen Charakter der Quellen auf der inhaltlichen Seite führte auch das fehlende Verständnis für die Organisation der Kompendien immer wieder zu Fehleinschätzungen. Ein gutes Beispiel hierfür ist der weitverbreitete »Obsequientraktat«, der in über der Hälfte aller Heroldskompendien überliefert ist. Dieser wird unabhängig voneinander einmal durch Colette Beaune ${ }^{189}$ - dem Wappenkönig von Flandern, ein anderes Mal durch Michel Popoff ${ }^{190}$ - dem Wappenkönig Toison d'or zugeschrieben, obwohl er tatsächlich keinem von beiden zugerechnet werden kann ${ }^{191}$. Die unterschiedlichen Zuweisungen erklären sich dabei aus den beiden unterschiedlichen Handschriften bzw. Heroldskompendien, aus denen die Autoren ihre jeweilige Version des Textes bezogen. So zitierte Colette Beaune den Traktat nach der Handschrift Paris, BnF, fr. 1280, an deren Entstehung auch der Wappenkönig von Flandern beteiligt war. Michel Popoff hingegen beruft sich auf eine Überlieferung in der Handschrift Paris, BnF, fr. 23988, die als einzigen mit einem Namen versehenen Text den kurzen »Traktat des Toison d'or zu den Wappenminderungen« enthält.

187 Melville, Hérauts et héros, S. 83.

188 LESTER, Literary Activity, S. 223 m. Anm. 3.

189 Vgl. Beaune, Mourir noblement, S. 138 m. Anm. 70 und v.a. S. 141.

$190 \mathrm{Vgl}$. PoPOFF, »Ainsi que faire se doit«, S. 5.

$191 \mathrm{Zu}$ diesem Traktat siehe unten, Kap. 4.2.1. 
Diese vereinzelte Namensnennung brachte Toison d'or an anderer Stelle zudem auch schon die Urheberschaft für den ebenfalls darin enthaltenen »MontjoyeTraktat« bzw. gleich für die gesamte Kompilation ein ${ }^{192}$. Während Colette Beaune ihre Zuweisung dabei völlig unkommentiert läßt, begründet Michel Popoff die seine mit dem schlichten Hinweis auf den Stil des Textes, den er als »lourd et imprécis « beschreibt und damit dem des Toison d'or in dem genannten Wappentraktat ähnlich ${ }^{193}$.

In die gleiche Kategorie fällt auch Jean-Bernard de Vaivres Zuweisung der Handschrift Paris, BnF, fr. 5241 an Merlin de Cordebeuf, dessen Beschreibung eines Turniers nach der Art der alten chevaliers errants hier ebenfalls der einzige Text ist, der von einem Verfasser gezeichnet ist ${ }^{194}$. Doch wurde dieser in der vorliegenden Kopie erst nachträglich angehängt, steht also mit der Entstehung der betroffenen Kompilationen in gar keinem Zusammenhang195.

\subsection{Ziel und Methode}

Die bisherige Auseinandersetzung mit den Heroldskompendien, deren bisheriges Verständnis und Handhabung stehen damit in keinem Verhältnis zu ihrer eigentlichen Bedeutung - von der fehlenden Wahrnehmung der Heroldskompendien auch für Fragen außerhalb des Heroldswesens und der Heraldik ganz zu schweigen. Ziel der vorliegenden Arbeit soll es daher sein, diese Quellengruppe als eigenständiges Phänomen aufzuarbeiten und einer breiteren Forschung zugänglich zu machen.

Unter dem Eindruck des aktuellen Kenntnisstandes und der gemachten Beobachtungen zum bisherigen Umgang mit den Heroldskompendien und deren Texten stellen sich folgende Aufgaben:

- Sammlung der Überlieferung und Eingrenzung der Quellengruppe,

- Charakterisierung der Struktur der Quellengruppe und ihrer Überlieferung,

- Charakterisierung der hier versammelten Inhalte und Herausarbeitung des spezifischen Quellenwertes der Heroldskompendien und ihrer Texte,

- Einordnung der Ergebnisse in ihren zeitgenössischen Kontext und Offenlegung des durch die Heroldskompendien möglichen Erkenntnisgewinnes zur spätmittelalterlichen Adelskultur wie zum Heroldsamt.

192 Die Zuordnung der Urheberschaft des Wappenkönigs Toison d'or für den »MontjoyeTraktat« geht gemeinhin auf dessen Edition in Du CANGE, Glossarium, S. 186-188, S. v. heraldus zurück. Als Verantwortlicher für die gesamte Kompilation wird er für die Handschrift BnF, fr. 23998 unter anderem im Catalogue général des manuscrits français. Anciens petits fonds français, Bd. II, S. 231 der BnF Paris genannt.

193 Ibid., S. 5.

194 Vgl. VAivre, La dégénérescence, S. 17. Zu dieser Kompilation siehe unten, Kap. 3.2.6.2.

195 Einer zweiten Überlieferung dieser Kompilation in einer weiteren Handschrift - hier ohne den Text des Cordebeuf - erging es dabei nicht besser. Sie wurde von Marius Barroux einfach dem möglichen Besitz des René d'Anjou zugeordnet, nur weil in einem der Texte dessen Großvater Louis d'Anjou genannt wurde, vgl. BARROux, Les fêtes royales, S. 9. 
Wie aber an anderer Stelle bereits deutlich gemacht werden konnte, reicht ein einfaches deskriptives Vorgehen für das Verständnis der Heroldskompendien bei weitem nicht aus ${ }^{196}$. Denn zum einen besaßen sie nicht jenen engen Bezug zu den realen Verhältnissen, welchen man ihnen auf den ersten Blick gern zu unterstellen bereit ist. So werden unter anderem Zeremonien besprochen, deren Beschreibung ohne weiteres den Anschein macht, aktuellen Bedürfnissen zu entsprechen. Bei genauerem Hinschauen stellt sich jedoch heraus, daß diese bereits seit Jahrzehnten außer Gebrauch waren. Zum anderen war ihre Überlieferung nicht auf das Heroldswesen beschränkt. Zu ihrem Rezipientenkreis zählten am Ende vor allem adelige Leser.

Damit ist über das rein Deskriptive hinaus auch eine erste Analyse vonnöten, die sich den aufkommenden Fragen zur Überlieferungsgeschichte, zum Gebrauch und der Intention der Handschriften stellt, deren Beantwortung für ein adäquates Verständnis dieser Quellengruppe unabdingbar ist. Dieser Anforderung soll die vorliegende Arbeit insbesondere durch zwei methodische Zugänge gerecht werden:

Zum einen sollen zur Untersuchung der Überlieferungsgeschichte der einzelnen Heroldskompendien insbesondere die Zeugnisse ihrer originären Überlieferung in den Mittelpunkt gestellt werden. Das bedeutet, daß sich die Untersuchung zuallererst an den Textträgern orientiert, nicht an den Texten selbst. Maßgeblich für die Aufnahme in das zu bearbeitende Quellencorpus ist demnach nicht die Entstehungszeit der Texte selbst, sondern die der Handschriften, die diese überliefern. Fragen nach Anlage und Struktur der Dokumente, deren Ausstattung und Datierung, vor allem aber nach deren Auftraggeber und Besitzer sollen dabei im Vordergrund stehen.

Dies führt auf der einen Seite zwar zu einer Einschränkung des für die Untersuchung zur Verfügung stehenden Quellenbestandes. Doch offenbart die jedem einzelnen Manuskript eigene strukturelle wie materielle Individualität auf der anderen Seite einen so tiefen Einblick in den intendierten Gebrauch der einzelnen Handschriften und in die Mechanismen der Überlieferung der darin enthaltenen Texte, daß diese Limitierung ohne weiteres gerechtfertigt ist. Denn durch die Analyse ihrer Textträger kann das aus den Texten gewonnene Bild noch einmal grundlegend an deren Stellung in der sozialen Wirklichkeit relativiert werden.

Wenn aber, wie zu zeigen sein wird, ein Teil der Heroldskompendien in eine adelige Überlieferung überging, so stellt sich zugleich die Frage, worin die spezifische Attraktivität bestand, welche diese auf den Adel ausübten, wie nach der Intention, welche die Herolde bei deren Abfassung beziehungsweise Kompilation originär verfolgten. Hierzu sollen ausgewählte Texte der Heroldskompendien näher untersucht werden. Dabei sollen einerseits deren Natur und Herkunft im Vordergrund stehen, soweit sich diese in einer gangbaren Weise nachvollziehen lassen. Vor allem aber ist nach dem besonderen Charakter dieser Texte zu fragen, wozu deren Inhalte analytisch nach Handlungswissen und Referenzwissen zu

196 Vgl. Hittmann, Information et tradition textuelle. 
unterscheiden sind ${ }^{197}$. Handlungswissen meint dabei jenes Wissen, welches die Herolde in ihren Aufgaben unmittelbar anleitete oder ihnen bei deren Erfüllung direkt behilflich war. Unter Referenzwissen hingegen soll jenes Sekundärwissen verstanden werden, das ihnen darüber hinaus auch ein weiter gefaßtes Verständnis der adeligen Kultur wie ihres eigenen Amtes vermittelte.

Diese Unterscheidung kann dabei parallel zu der oben beiläufig intendierten Gegenläufigkeit zwischen den konkreten Aufgaben der Herolde und ihrer sozialen Funktion verstanden werden. Im ersten Falle wäre damit jenes Wissen gemeint, welches sie unmittelbar in der Ausübung ihrer alltäglichen Aufgaben zur Anwendung brachten, sei es bei der Ausrufung von Turnieren, ihrer Teilnahme an Obsequien oder in ihrer Funktion als Boten. Das Referenzwissen hingegen würde den nötigen Hintergrund stellen für ihr Verständnis von Ruhm und Ehre, von adeligen Zeremonien und ritterlichem Verhalten, das sie in ihren Berichten und anderen Äußerungen vermittelten.

Bereits die strikte Ausrichtung an der materiellen Überlieferung macht jede weitere Einschränkung des Quellencorpus nur umso restriktiver. Da jedoch - was die Bedeutung dieser Quellen unterstreicht - von deren Anfängen bis zum 17. Jahrhundert weit über neunzig Überlieferungen von Heroldskompendien erhalten sind, ist der zu untersuchende Quellenbestand im Interesse einer gangbaren Untersuchung noch weiter einzuschränken. Dies soll durch räumliche und chronologische Vorgaben geschehen.

So soll sich die Arbeit nur auf Handschriften aus einem weiter gefaßten, französisch-burgundischen Kulturraum beschränken. Die Gründe hierfür sind eindeutig. Denn bei den Heroldskompendien handelt es sich um ein Phänomen, das vor allem im Frankreich und Burgund der zweiten Hälfte des 15. Jahrhunderts weite Verbreitung fand. Aus dem deutschen Sprachraum hingegen ist bisher nur ein einziges Beispiel bekannt ${ }^{198}$. Aus Spanien gibt es nur Spuren gleichartiger Texte oder Textsammlungen ${ }^{199}$. Einer besonderen Begründung hingegen bedarf der Ausschluß Englands, wo wiederum die Situation des Heroldsamtes eine völlig andere ist. Bereits 1417 erhielten die Herolde hier kollektive, offiziell verbriefte Privilegien und klar formulierte Aufgaben. Seit 1421 hielten sie gemeinsame Kapitel ab, die letztlich 1485/86 mit Stiftung eines gemeinsamen, festen Hauses in der Gründung des noch heute existierenden College of Arms mündeten. Ihnen gelang damit, was die französischen Herolde gut achtzig Jahre zuvor vergeblich versuchten: eine einheitliche und geschlossene Organisation des Heroldsamtes.

197 Die hier verwendete Terminologie entstand unter anderem aus einem gemeinsamen Gespräch mit Prof. Dr. Gert Melville, dem ich an dieser Stelle herzlich danken möchte. Zu den theoretischen Grundlagen dieser Unterscheidung siehe noch unten, S. 234, Anm. 1.

198 Vgl. Antwerpen, Stadsbibliotheek, Cod. 255 (B. 89420). Zu dieser Handschrift vgl. ausführlich VAN ANROOIJ, Hendrik van Heesel.

199 Bisher konnten keine entsprechenden Handschriften gefunden werden. Als Ansatzpunkt für weitere Studien zur spanischen Traktatliteratur zu den Herolden vgl. jedoch den von Diego de Valera verfaßten Traktat »Preheminencias y cargos de los oficiales d'armas «, ediert in: BALENCHANA (Hg.), Epístolas, S. 233-241. 
In England war das Amt daher bei weitem strukturierter, korporativer, hierarchischer organisiert als in Frankreich. Die Ausgangslage für die hier zu untersuchende Quellengruppe der Heroldskompendien war damit eine völlig andere, was sich auch in deren Überlieferung widerspiegelt. So wurden in England zwar weniger Texte produziert als in Frankreich, doch wurden diese auch breiter und deutlich homogener überliefert ${ }^{200}$. Ein größerer Teil der Texte war dabei auch direkt auf die Situation in England ausgerichtet. Auch diese in die vorliegende Studie mit einzubeziehen, hätte deren Rahmen deutlich gesprengt. Sie bilden eine Gruppe für sich und sind als solche auch zu behandeln.

Die Eingrenzung des Untersuchungsraumes auf Frankreich und Burgund orientiert sich dabei weniger an den politischen Grenzen denn an kulturellen Gemeinsamkeiten. So sind hier auch französisch geprägte Gebiete außerhalb der damaligen Grenzen des Königreiches mit einbegriffen, wie die Herzogtümer Savoyen und Lothringen. Gemeint sind letztlich jene Gebiete, für welche die vorliegenden Texte selbst Geltung beanspruchten. So heißt es zum Beispiel für die Durchführung der Turniere gemäß dem usage de France im »Kompendium des Herolds Sicile«:

C'est l'ordonnance du tournoy à présent scelon l'usage de France, qui comprend quant ad ce, Haynau, Brabant, Flandres, Hollande, Zéelande, et ce qui est par deçà le Rhein, Savoye, le Daulphiné, Langhedoe et Provence ${ }^{201}$.

Der Geltungsbereich für die Aufzählung der »Allgemeinen Privilegien der Herolde « im französischen Königreich ist ähnlich formuliert ${ }^{202}$. Ursprung dieser Einteilung mögen dabei die alten Wappenprovinzen gewesen sein, von denen Antoine de La Sale in seinem Turniertraktat berichtet. Demnach habe Karl der Große, als er Frankreich vom Reich trennte, beiden eine Wappenprovinz zugeteilt. Den Deutschen auf der einen Seite des Rheins die Mark Ruyers

et des parties par-deça le Rin, comprinses les basses Allemaignes et les subgetz de l'empire avec tout le royaume de France et aultres qui s'y joinderoient, seroit l'autre marche, laquelle seroit nommee en armes les Poyers ${ }^{203}$.

Später haben die Kaiser den Poyers zwar Gebiete ausgegliedert und neue Marken daraus gemacht, aber encores sont pluiseurs qui aux tournoiz ne appellent les Barbençons, les Haynuiers, les Lyegoiz, les Ardenoiz, les Hazebains et aultres de l'empire deça le Rin, fors que Poyers ${ }^{204}$.

Was nun Savoyen, den Dauphiné und die Provence angeht, welche ebenso bei Sicile genannt werden, so gehörten diese nach einhelliger Meinung der zeitgenössischen Quellen stets zur größten aller Provinzen der Poyers, der Wappen- bzw.

200 Vgl. z. B. London, BL, Cotton Nero D II, fol. 252-265; London, College of Arms, Arundel 26 (recte 63), London, BL, Add. 34801. Für die Edition zumindest eines Teiles der hier enthaltenen Texte vgl. Twiss (Hg.), The Black Book, Bd. I.

201 Roland (Hg.), Parties inédites, S. 184.

202 Ibid., S. 93.

203 Antoine de La Sale, Le traité des tournois, S. 300.

204 Ibid., S. $300 \mathrm{f}$. 
Adelsprovinz der Champagne. So liest man es bei Antoine de La Sale, und so wird es auch in einem weiteren, wohl in der Wende zum 16. Jahrhundert entstandenen Traktat zu den französischen Wappenprovinzen dargestellt, wo es heißt:

La marche de Champaigne qui est grande marche et est de la marche la ducé et conté de Bourgongne, la ducé de Bar, la ducé de Savoye, le Daulphiné, la conté de Vallentinois, la princhaulté d'Orenge, la conté de Venicy qui est au pappe, la conté de Provence et de Nice, la riviere de Gennes et bien avant es Ytalles, et sont touttes ces nations Champenois aux armes $^{205}$.

Der Untersuchungszeitraum schließlich ist auf die Zeit zwischen den Anfängen der Heroldskompendien am Ende des 14. Jahrhunderts und dem Beginn des 16. Jahrhunderts begrenzt (wo zugleich eine größere Lücke in der Überlieferung festzustellen ist). Der gewählte Rahmen umfaßt dabei nicht nur den Zeitraum von der Entstehung der ersten Heroldskompendien bis zu deren erstem Druck. Er deckt sich zugleich ganz augenfällig mit der Hochphase der Entwickung des Heroldsamtes, das insbesondere in der ersten Hälfte des 15. Jahrhunderts seine größte Bedeutung und gesellschaftlichen Einfluß erlangte. Die Heroldskompendien scheinen sich damit in genau dieselben gesellschaftlichen Wandlungsprozesse des ausgehenden Mittelalters einzuordnen wie ihre (ursprünglichen) Kompilatoren, womit zugleich deren möglicher Erkenntnisgewinn umrissen ist. Denn der veranschlagte Zeitraum überblickt genau jenen Prozeß, der im Zentrum der folgenden Untersuchung stehen soll: Der Übergang der Heroldskompendien von einer vorrangig von den Herolden zu einer vorrangig adelig geprägten Überlieferung.

Aus alledem ergibt sich für die Arbeit folgendes Vorgehen:

Eingrenzung der Quellengruppe und Beschreibung des Überlieferungskontextes

Ausgangsbasis der vorliegenden Arbeit bilden die Daten von fast 500 Sammelhandschriften mit über 2700 Traktatüberlieferungen, welche nach einem weitgefaßten Raster hinsichtlich ihres thematischen Bezuges zur Adelskultur und dem Heroldswesen zusammengetragen wurden ${ }^{206}$. Aus diesem inkohärenten Bestand gilt es daraufhin die Gruppe der potentiellen Heroldskompendien herauszufiltern. Hierbei sollen jene Kriterien zu Inhalt und Intention der Heroldskompendien helfen, welche aus einer näheren Analyse des bekanntesten, vor allem aber elaborier-

205 Paris, BnF, n.a.fr., 1075, fol. 36r-38v, hier fol. 36r-36v.

206 Für die Suche nach den entsprechenden Handschriften hat sich insbesondere der Katalog zu den Überlieferungen französischer »Traités de blason« im Anhang der unveröffentlichten Dissertation von Claire Boudreau als äußerst hilfreich erwiesen, vgl. BoudREAU, Traités de blason, Bd. III. Aus dieser Arbeit ging eine umfassende und sehr hilfreiche Enzyklopädie des heraldischen Wissens von den Anfängen der Wappenkunde bis zum 16. Jahrhundert hervor, die Claire Boudreau 2006 in drei Bänden veröffentlichte (vgl. ID., L'héritage symbolique). Ihre inhaltlichen Ausführungen zur Entwicklung der Blasonierungstraktate (Bd. I der unveröffentlichten Dissertation) sowie die hier mit großem Gewinn verwendeten Übersichten zu deren handschriftlicher Überlieferung (ibid., Bd. III) blieben dabei leider unveröffentlicht. 
testen Exponenten dieser Quellengruppe, dem »Kompendium des Herolds Sicile«, gewonnen wurden.

Unter der gemachten Einschränkung auf Handschriften (und Drucke) französisch-burgundischer Provenienz bis zum Beginn des 16. Jahrhunderts verbleibt schließlich eine Gruppe von insgesamt 25 Überlieferungen zur Untersuchung. Damit steht der vorliegenden Arbeit eine kritische Menge zur Verfügung, die allgemeine Aussagen zuläßt und für die Untersuchung als repräsentativ gelten kann, und nichtsdestotrotz handhabbar bleibt.

Die Abgrenzung dieser Überlieferungen von ihrem breiteren Überlieferungsumfeld bleibt dennoch prekär. Daher soll in einem weiteren Schritt auch dieses näher beschrieben und die Einbindung der Heroldskompendien in größere Überlieferungszusammenhänge erläutert werden.

Beschreibung und Analyse der Anlage und Überlieferung der Heroldskompendien

Die zusammengetragenen Handschriften gilt es dann auf deren Anlage und Überlieferung hin zu untersuchen. Dabei ist zuerst die allgemeine Struktur der Heroldskompendien, allen voran deren kompilatorischer Charakter zu erläutern. In einem zweiten Schritt sind dann die einzelnen Überlieferungen miteinander in Beziehung zu setzen und nach textlichen Gemeinsamkeiten zu gruppieren, um sie abschließend jede für sich als individuelles Zeugnis der Überlieferung zu beschreiben. Dabei ist insbesondere nach der Geschichte und dem Hintergrund der einzelnen Handschriften (bzw. des Druckes) zu fragen, nach deren Anlage, Ausstattung und Provenienz. Die daraus resultierenden Beobachtungen sind am Ende vergleichend zusammenzufassen.

Beschreibung und Analyse der Überlieferung nach deren Inhalt

Auf die Auswertung der Überlieferung der Texte folgt deren inhaltliche Analyse. Die inhaltliche Annäherung folgt dabei jener thematischen Dreiteilung, die sich aus der Beschäftigung mit dem »Kompendium des Herolds Sicile« heraus für die Heroldskompendien als grundlegend erweist:

- Texte zum Heroldswesen selbst,

- Texte zu adeligen Zeremonien,

- Texte zur adeligen Gesellschaft und deren Zeichen.

Einer kurzen Gesamtschau, die jeweils die Vielfalt der überlieferten Texte und Inhalte kenntlich macht, soll nach den oben erläuterten Gesichtspunkten die Analyse einzelner, für die jeweilige Themengruppe exemplarisch ausgewählter Texte folgen.

\section{Schluß}

Mit einem kurzen Abriß zur Geschichte der Heroldskompendien und ihrer Überlieferung sollen die Ergebnisse der Untersuchung abschließend zusammengefaßt und in ihren zeitgenössischen Kontext eingeordnet werden. Dabei sind insbesondere deren Quellenwert und Erkenntnispotential herauszuarbeiten und näher zu 
bewerten, um die Heroldskompendien der Forschung schließlich als weitere, bisher kaum beachtete Quellengruppe zur spätmittelalterlichen Adelskultur anzuempfehlen.

\section{Anhang}

Der Untersuchung sind zwei Übersichten angehängt. Die erste gibt einen Überblick über die am häufigsten in den Heroldskompendien enthaltenen Texte. Die zweite listet in thematischer Ordnung alle hier überlieferten Texte auf. Genannt sind dabei deren jeweils am weitesten verbreiteten zeitgenössischen Titel, ihr Incipit, der in der vorliegenden Studie vergebene Arbeitstitel sowie eine Liste ihrer Überlieferungen in den hier untersuchten Handschriften und etwaiger Editio$n^{207}$. Damit soll dem Leser das notwendige Material an die Hand gegeben werden, die vorliegende Interpretation fortzusetzen und zu vertiefen, in der Hoffnung, daß die hier neu erschlossene Quellengruppe der Heroldskompendien mit ihren vielfältigen Texten und Themen die Perspektiven künftiger Arbeiten zu erweitern vermag.

207 Die detaillierte Beschreibung aller Handschriften (und des einen Druckes), die die Grundlage dieser Untersuchung bilden, sowie weiterer Handschriften aus dem näheren Überlieferungskontext, die in der dieser Arbeit zugrundeliegenden Dissertation enthalten war, mußte für die vorliegende Veröffentlichung leider entfallen. Sie wird später separat nachgereicht. 
